\title{
How does an axon grow?
}

\author{
Jeffrey L. Goldberg ${ }^{1}$ \\ Department of Neurobiology, Stanford University School of Medicine, Stanford, California 94305, USA
}

How do axons grow during development, and why do they fail to regrow when injured? In the complicated mesh of our nervous system, the axon is the information superhighway, carrying all of the data we use to sense our environment and carry out behaviors. To wire up our nervous system properly, neurons must elongate their axons during development to reach their targets. This is no simple task, however. The complex morphology of axons and dendrites puts neurons among the most intricate and beautiful cells in the body. Knowledge of how neurons extend axons and dendrites, elongate at a particular rate, and stop growing at the proper time is critical to understanding the development of our nervous system, yet the regulation of these processes is poorly understood. Considerable attention in recent years has focused on understanding how growth cones are guided and steered through complicated pathways (for review, see Schmidt and Hall 1998; Mueller 1999), and even how neurons initiate new processes (for review, see Da Silva and Dotti 2002), but what mechanisms are involved in elongation itself? Are environmental signals needed to drive axon growth and, if so, what are the intracellular molecular mechanisms by which they induce elongation? What controls the rate of axon growth? How do CNS neurons know whether to extend axons or dendrites? Is the signaling of axon versus dendrite growth attributable to different extracellular signals, different neuronal states, or both? All of these questions bear critically on our understanding of axon growth and here I review recent answers and approaches to the above questions, and highlight their relevance during development, injury, and disease.

\section{How does an axon grow?}

Axons are generally on the scale of $1 \mu \mathrm{m}$ thick and some are more than $1 \mathrm{~m}$ long, making neurons the largest cells in the body by both volume and surface area. Sustaining such massive growth, however, requires the interplay of many factors-producing membrane and cytoplasmic elements in the proper proportions; shipping these building blocks to the right compartment and inserting them into the growing axon; and coordinating the timing of all of these with the growth cone's moment-by-moment de-

${ }^{1}$ E-MAIL jeffrey.goldberg@stanford.edu; FAX (650) 725-3958. Article and publication are at http://www.genesdev.org/cgi/doi/10.1101/ gad.1062303. cisions to advance, retract, pause, or turn (Fig. 1). All of these are potential regulatory sites that could control a neuron's ability to elongate or regenerate its axon.

Production of the building blocks, both membrane and cytoplasmic

Rapid axon growth requires rapid manufacture and supply of cytoplasm and membrane. Where are the lipid and protein building blocks made? It was known from classic experiments that axons cut off from the cell bodies of adult sensory neurons continue to elongate in culture (Shaw and Bray 1977), but evidence for local production of membrane and cytoplasmic elements went lacking for decades. Secreted proteins, both transmembrane and extracellular, as well as glycolipids are likely synthesized at the cell body, where the rough endoplasmic reticulum (ER) and golgi complex are located, and shipped in vesicles down the axon for membrane insertion. What about other lipids? Blocking lipid synthesis interferes with axon growth (Posse de Chaves et al. 1995a,b), although it is not clear how much this represents dependence on supply from the cell body or from the axon. Smooth ER is located throughout the axon, however, and experiments using radioactive lipid precursors added to axons but not to the cell bodies of neurons either in compartmented cultures (Fig. 3, below) or in vivo show that at least some lipid synthesis can occur in axons (Gould et al. 1987a,b; Vance et al. 1991, 1994; Posse de Chaves et al. 1995b). Similarly, experiments in sympathetic neurons demonstrate that the cell body is responsible for cholesterol synthesis, but if synthesis is insufficient or is blocked pharmacologically, both the cell body and axons can take up cholesterol from high-density and low-density lipoproteins, locally gathering needed material from an external source (Vance et al. 1994; Posse de Chaves et al. 1997, 2000). From these various experiments it appears that the major burden of producing plasma membrane must fall to the cell body, but it may be that longer axons in vivo rely more heavily on local, axonal production of these building blocks.

Until recently, cytoplasmic proteins for axons were similarly thought to be entirely cell body-derived, but the possibility of local, intra-axonal production has received new support. Ribosomes and mRNAs have been localized to mammalian axons, suggesting at least a possible role for axonal translation (Tennyson 1970; Bassell et al. 1998; Koenig et al. 2000), as had been found previ- 


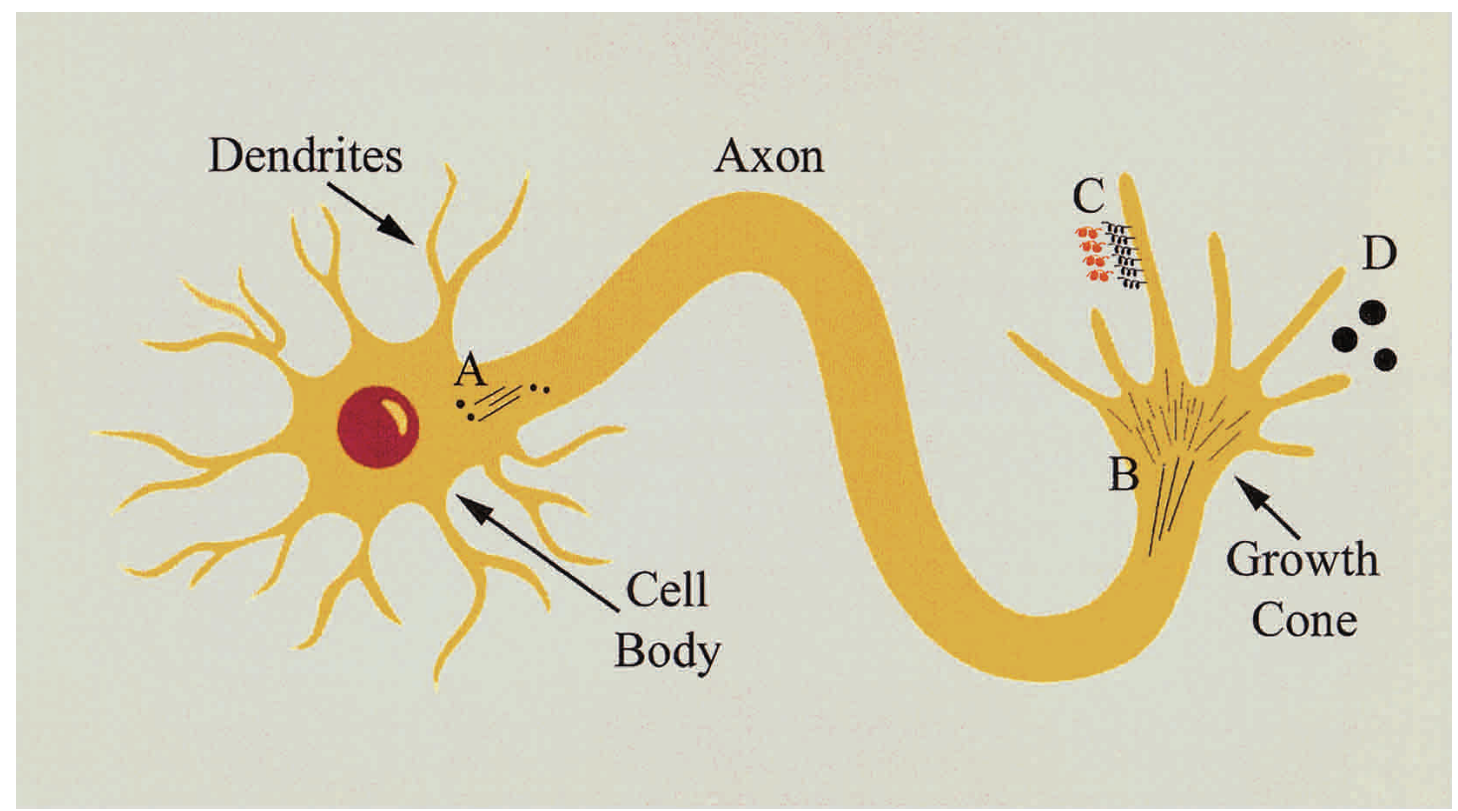

Figure 1. Axon growth, like an automobile, requires (A) the supply of building blocks (gasoline); as well as (B) cycling filaments in the growth cone (the running motor); (C) connections between growth cone filaments and the growth substrate (the clutch); and (D) a way to translate external, directional cues into pathfinding decisions (the steering wheel). Steps forward in our understanding of these processes and their regulation are the subjects of this review.

ously for dendrites (for review, see Job and Eberwine 2001). Furthermore, severed axons locally synthesize such axonal structural building blocks as neurofilaments, tubulin, and actin (Eng et al. 1999; Zheng et al. 2001). Intriguingly, axonal localization may be specific for axon growth-related processes-only $\beta$-actin mRNA is enriched in neurites and growth cones, corresponding to $\beta$-actin protein's localization to distal growth cones and filipodia of actively growing neurites in vitro (Bassell et al. 1998) and in vivo (Weinberger et al. 1996). In contrast $\gamma$-actin protein is localized throughout the cell body and neurites of embryonic cortical neurons, and $\gamma$-actin mRNA is not enriched in growing axons.

The axonal localization of specific mRNAs raises the question, is there any physiologic contribution made by these mRNAs? Recent experiments suggest that they are not there by accident. In adult dorsal root ganglion (DRG) neurons in vitro, blocking axonal protein synthesis causes growth cones to retract, but only when the axons are cut off from the cell body. These experiments suggest that axonal translation is sufficient to maintain the growth cone, at least over short periods of time, but that axonal translation is not necessary if cell body-mediated protein synthesis is available (Zheng et al. 2001). Embryonic Xenopus retinal axons cut off from their cell bodies can elongate and turn in vivo (Harris et al. 1987) and in vitro in response to guidance cues (Campbell and Holt 2001). After adding protein synthesis inhibitors, they fail to respond to steering cues from soluble guidance molecules netrin-1 or Sema3a (Campbell and Holt 2001). All of these data are consistent with the hypothesis that axonal protein synthesis is constantly required to resensitize the growth cone to guidance cues; without axonal protein synthesis the growth cone otherwise adapts and stops responding (Ming et al. 2002).

In studies of Xenopus neurons in culture, which exhibit a presynaptic potentiation in response to the soluble trophic factor brain-derived neurotrophic factor (BDNF), blocking protein synthesis for 45 min before BDNF application had no effect, but a 2-h blockade completely eliminated the presynaptic response to BDNF. This led the authors to hypothesize that protein synthesis in the axon terminals may not be specifically induced by BDNF, but rather that constitutive ongoing protein synthesis is required for the response to BDNF (Zhang and Poo 2002).

The specific induction of protein synthesis in axons was demonstrated beautifully using chick spinal cord axons, which normally up-regulate axonal expression of the EphA2 guidance receptor after crossing the midline (Brittis et al. 2002). An RNA reporter construct consisting of green fluorescent protein (GFP) RNA followed by the 3' untranslated region (UTR) of EphA2 RNA was transfected into these neurons using electroporation. Brittis and colleagues (2002) found that GFP expression was specifically up-regulated in the distal axons and growth cones of these spinal neurons only after the axons crossed the midline, suggesting that a local protein synthesis mechanism was being activated in response to extracellular cues and was mediated by the EphA2 3'UTR sequence (Brittis et al. 2002). These experiments provided evidence that localized protein synthesis is critical to rejuvenating and changing the growth cone's responsiveness to various environmental signals.

Although in the presence of the connected cell body axonal protein synthesis may not be necessary for 
growth, these experiments point to a physiologic role for local protein synthesis. Could local protein synthesis also have a role in axon elongation or regeneration? The response to axonal injury may include an initial period wherein axonal synthesis may be crucial to maintaining the growth cone to allow the cell body time to jumpstart into regeneration mode. Support for this hypothesis comes from studies of crushed peripheral nerves regenerating into silicone sleeves loaded with the translational inhibitor cycloheximide, which inhibited elongation rates by nearly 60\% (Gaete et al. 1998). Despite such promising data, questions remain: is axonal protein synthesis physiological during development, and is its regulation critical for regeneration in the adult?

\section{Extending the plasma membrane}

Membrane insertion is critical for axon growth, as blocking the transport of membrane vesicles rapidly brings axon growth to a halt (Klausner et al. 1992; Martenson et al. 1993). Yet the identification of where new membrane is inserted is still the subject of debate-is it preferentially at the growth cone, the cell body, or all along the axon? Visualization of fluorescent vesicles leaving the cell body in Xenopus neurons in culture suggests insertion at the growth cone (Zakharenko and Popov 1998), and transfecting an exogenous gene into cultured rat hippocampal neurons similarly demonstrated insertion of the newly synthesized proteins at the growth cone first
(Craig et al. 1995). On the other hand, in vivo metabolic labeling studies suggest that certain proteins and lipids are inserted all along the axon (Griffin et al. 1981; Toews et al. 1988; Harel and Futerman 1996), and physically stretching the axon leads to remarkably rapid axon elongation and new membrane insertion along its length (Zheng et al. 1991). Axon stretching may be relevant after the growth cone has reached its target during development but the axon continues to elongate as the animal grows. Both pan-axonal and growth cone-specific insertion could be important. For example, rapidly extending growth cones could mimic such stretching by producing tension along the axon, thereby inducing membrane insertion all along the axon, whereas a slowly extending growth cone might only allow membrane insertion at the growth cone itself (Futerman and Banker 1996). In addition, insertion of different vesicle subsets could be preferentially inserted along the axon and at the growth cone, reflecting the need for different membrane components and different signaling receptors in each compartment. Therefore production and shipping of these basic building blocks is clearly critical to axon elongation, but the regulation of these processes remains mysterious.

\section{The growth cone: motor and clutch of axon growth}

Better studied in recent years is the growth cone, the mobile tip of the axon specialized for elongation and

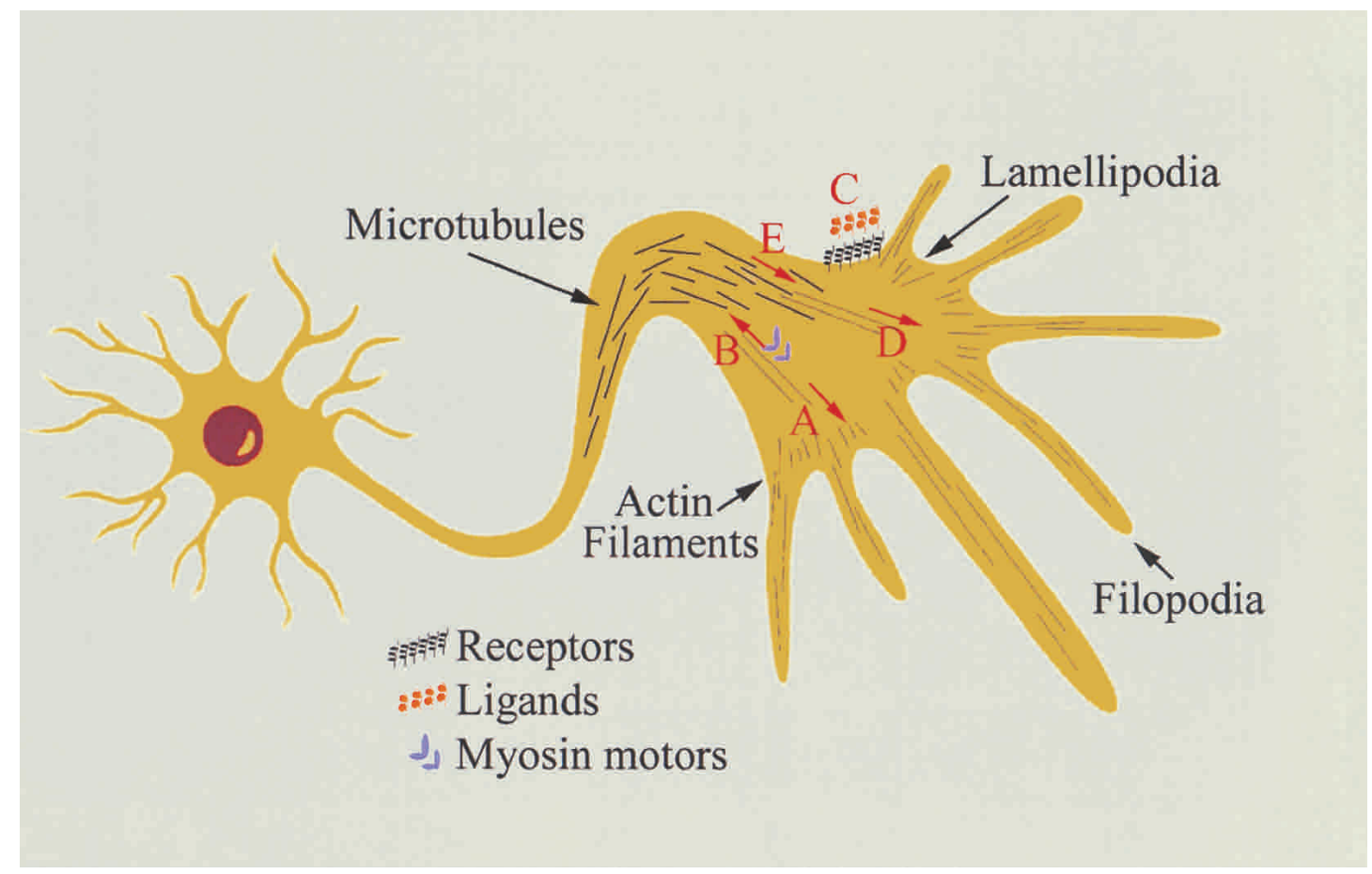

Figure 2. In the peripheral domain, including in the actin-rich filopodia and lamellipodia, actin filaments polymerize toward the leading edge (A) but are dragged back toward the central domain by myosin-like motors (B), leading to a balanced equilibrium of no net progress. In addition, retrograde flow keeps the microtubules from penetrating into the peripheral domain (B). Signals from surface receptors bound to ligands, such as adhesive substrates (C), suppress the retrograde flow of actin filaments, and the balance shifts toward polymerization-driven forward progress of actin filaments (D). In addition, the lack of retrograde flow allows microtubule polymerization to proceed into the peripheral domain $(\mathrm{E})$, extending the axon itself forward. 
steering, and the molecular mechanism of growth cone mobility can be described as the motor and clutch of axon elongation (Fig. 1; Mitchison and Kirschner 1988). The growth cone is responsible for generating forward tension on the elongating axon (Lamoureux et al. 1997). Neuronal growth cones exhibit two primary domains characterized by two different types of cytoskeletal filaments: a central domain with microtubules that is generally continuous with the axon that precedes it, and a peripheral domain rich in actin filaments (Fig. 2). Actin monomers in the peripheral domain undergo constitutive plus end-directed filament assembly, elongating the filament in the distal tips of lamellipodia and filopodia and pushing the growth cone membrane in the forward direction; simultaneously the entire actin filament is dragged back by myosin-like molecular motors into the central domain where the actin filaments depolymerize (Forscher and Smith 1988; Tanaka and Sabry 1995; Mitchison and Cramer 1996). At the tail end of these actin filaments, the myosin-mediated retrograde flow blocks microtubules from advancing into the peripheral domain, and blocks the advance of the growth cone's central domain and therefore of the axon itself (Forscher and Smith 1988). The balance of anterograde polymerization and retrograde retraction determines the advance of these actin-rich structures in the peripheral domain; for example, blocking myosin activity causes filopodial elongation (Lin et al. 1996). When the rate of these two processes balance perfectly, the motor sits in neutral, and the growth cone neither advances nor retracts. This is the running motor of axon elongation, waiting to be engaged.

How is this running motor engaged by extracellular signals to advance? The growth cone's grasp on an adhesive substrate must translate across the membrane and evoke the cytoskeletal changes needed for axonal growth. Work on a molecular model for engaging the clutch and letting the running motor push the growth cone forward has seen rapid progress (Suter and Forscher 2000). When the growth cone interacts with a substrate or cell-adhesion molecule, an increasingly strong connection is formed between the growth cone's surface receptors and the underlying actin network-the molecular clutch is engaged. The localization of extracellular adhesions to specific subdomains of the growth cone may dictate how the adhesion signal is interpreted-for example, for filopodial growth versus axon growth (Steketee and Tosney 2002). The link from membrane adhesion to actin cytoskeleton is sufficient to overcome the force created by myosin motors and retrograde flow is thereby decreased (Suter et al. 1998). As actin polymerization continues at the leading edge, however, the balance is shifted toward forward protrusion of actin filaments in the tips of lamellipodia and filopodia. Simultaneously, the decrease in retrograde flow is accompanied by unimpeded microtubule polymerization into the peripheral domain, moving the central domain of the growth cone forward and thereby elongating the axon (Lin and Forscher 1995). One question raised by this model is whether axon growth speed is regulated by one aspect of these dynamics, for example by varying the rate of retrograde flow, the tendency toward actin filament polymerization, or the strength of clutch engagement.

A crucial question is how interactions at the plasma membrane are communicated to the cytoskeleton. Therefore, much recent effort has gone into characterizing the control of actin activity in the growth cone, or in the analogous lamellipodia and filopodia of migrating cells. Various receptor families including integrins, catenins, and cadherins recruit specific linker proteins to transduce signals from the membrane to the cytoskeleton, and these linker proteins are critical both for binding the cytoskeleton directly, as well as to initiate cascades of cellular kinases that can amplify and diversify the signal. For example, integrin receptors bind integrinlinked kinase (ILK), a multifunctional protein that is able both to recruit other adaptor and scaffolding proteins to the sites of cell adhesions and thereby bind actin filaments, and to simultaneously phosphorylate other signaling proteins like protein kinase B and GSK-3 (for review, see Wu and Dedhar 2001).

Slightly downstream of membrane receptors and their associated signaling components are the rho-GTPases, a family of regulators of actin motility, intensively studied for the critical role they have in axon guidance as well as axon initiation and elongation. Because their role in axon guidance has received excellent review in recent years, discussion here will remain brief (Schmidt and Hall 1998; Mueller 1999; Braga 2002). The rho-GTPases and the effector kinases they activate have been linked directly to growth cone motility by virtue of their effects on myosin contractility and retrograde actin flow, and on actin polymerization and stabilization. Rho, rac, and cdc42 GTPases are active when bound to GTP, and inactive after hydrolyzing GTP to GDP, and therefore are activated by guanine nucleotide exchange factors (GEFs) and and more quickly inactivated by GTPase-activating proteins (GAPs). In its active state, rho generally promotes growth cone collapse, and inhibiting rho generally leads to an increase in neurite outgrowth; conversely the rac and cdc42 generally increase the filopodial and lamellipodial activity important for elongation. The GEFs and GAPs, as well as the effector kinases downstream of these GTPases are likely responsible for the specificities of their effects on axon initiation, elongation, and guidance (Patel and Van Vactor 2002). For example, inhibiting rhoA in cerebellar granule neurons with the C3 enzyme leads to an increase in axon initiation and elongation; inhibiting a rhoA effector kinase p160ROCK leads to an increase in axon initiation without affecting elongation (Bito et al. 2000). These effects correlate with alterations in motility at the growth cone, supporting the hypothesis that much of the regulation of axon growth is carried out there. The interplay between these growth cone dynamics and the rest of the cellular processes necessary for axon growth are just beginning to be appreciated.

Downstream of the rho-family GTPases and their effector kinases, numerous actin-binding proteins have been identified in growth cones and found to be modulators or effectors of axon growth. Enhancing plus-end actin polymerization, decreasing retrograde actin flow, 
and enhancing minus-end actin depolymerization could all contribute to increased rates of axon elongation, and regulation of proteins with all three of these mechanisms have been found to influence axon growth. For example, the actin monomer-binding protein profilin can enhance actin polymerization, and is recruited to the leading edge of growth cones by the Enabled family of proteins including Mena, which themselves are target substrates of such tyrosine kinases as Abl. Knockouts of these genes in Drosophila and in mice interfere with axon growth and pathfinding (Lanier et al. 1999; Wills et al. 1999a,b). At the transitional zone between actin tails and microtubules, the actin filament-severing protein gelsolin and the filament depolymerizing family of ADF/ cofilin proteins increase actin turnover. Growth cones from gelsolin knockout mice fail to retract their filipodia (Lu et al. 1997), and ADF/cofilin activation increases neurite outgrowth (Meberg et al. 1998). Another actin monomer-binding protein, $\beta$-thymosin, is enriched in growth cones and is up-regulated in regenerating zebrafish RGCs (Roth et al. 1999). An important area for further research is to understand the exact functional roles of these actin-binding proteins, and how they are coordinately regulated to elicit axon growth.

Actin is not responsible for all the action, however. Microtubules and microtubule-associated proteins (MAPs) are thought to be critical for axon and dendrite growth. In growth cones, microtubules can be directly stimulated to polymerize forward into the peripheral domain independently of decreases in retrograde actin flow (Kabir et al. 2001), and cell adhesion molecules can also signal changes in microtubule stability through a variety of signaling pathways (for review, see Braga 2002). Microtubule destabilization is required for the insertion of new membrane in the growth cone (Zakharenko and Popov 1998). MAPs, most of which are thought to promote and stabilize microtubule polymerization, are key players as well. Knocking out dendritic MAP2 decreases dendritic growth in vivo (Harada et al. 2002), and decreasing expression of the MAP tau in at least some experiments inhibits axon outgrowth and decreases the size and motility of the growth cone (Liu et al. 1999). The regulation of tau by differential phosphorylation may be critical to its role in stabilizing or destabilizing microtubules as needed along the axon or at the growth cone, respectively (Biernat et al. 2002). There may be significant redundancy in MAPs, as double knockouts of MAP2 and MAP1b and of tau and MAP1b appear to amplify these effects on dendrites and axons, respectively (DiTella et al. 1996; Takei et al. 2000; Teng et al. 2001). Another axonal MAP named collapsin response mediator protein-2 (CRMP-2) binds tubulin dimers and stimulates axon growth and branching in hippocampal neurons in culture (Fukata et al. 2002). Finally, microtubule motors such as dynein actively transport microtubules along the length of the axon, are required for axon growth, and may contribute to the microtubule invasion of growth cones during elongation (Ahmad et al. 1998). Together, these data support a role for active regulation of microtubule activity in the control of axon outgrowth.
Does cellular growth limit axon growth, or vice versa?

The need for so many building blocks to sustain axon growth raises a question. Is the rate of axon growth limited by supply of these molecules? If cell body-dependent growth processes, including at a minimum the supply of mRNA for protein synthesis, are tightly tied to and limiting for axon growth, cutting off the supply should halt axon growth immediately. At the other extreme, if the axon does not rely at all on the cell body, axon growth might proceed indefinitely. In the experiments discussed above in which axons were cut off from their cell bodies, the axons continued to progress at approximately their previous rate (Campbell and Holt 2001). The experiment was only maintained over the course of a few hours, and the authors did not address whether the length of axon immediately after it was cut predicted the length of time it could continue to extend, but the results suggest that cellular growth is not an immediately limiting factor for axon growth. Similarly, inhibiting protein or lipid synthesis does not inhibit axon growth on the scale of hours (Lein and Higgins 1991; Posse de Chaves et al. 1995b; Schwarz et al. 1995; Harel and Futerman 1996). In other experiments analyzing sensory neurons with multiple neurites, the activity of the multiple growth cones remained completely independent-fast growth of one neurite was not compensated for by slower elongation or retraction of the other neurites. Furthermore, other neurites did not slow even when mechanical tension was applied to stimulate even faster growth from one neurite (Lamoureux et al. 1998). These data may differ when two branches of the same axon are challenged to compete, as has been observed in hippocampal neurons in culture (Ruthel and Hollenbeck 2000), or in an aplysia neuron when an appropriate target cell is present (Goldberg and Schacher 1987).

Another way to elongate, or increase in volume, without adding cell mass is to regulate cytoplasmic density. For example, as axon diameters grow, neurofilament packing density decreases (Hall et al. 2000), the likely result, at least in part of phosphorylation, increasing cell volume rapidly without increasing cell weight. A similar effect is seen during myelination of axons, where over a relatively short period axons increase in diameter, often doubling the volume of the cell (de Waegh et al. 1992; Starr et al. 1996). Whether a similar expansion in volume is possible along the longitudinal axis of the axon is currently unknown. Nonetheless, taken together these experiments suggest that cellular growth is providing sufficient oversupply to keep the axon in an elongating mode, and that growth cone procession is the limiting factor in axon growth.

\section{What signals induce axon growth?}

Do neurons need specific extrinsic signals for axon growth?

Significant progress has been made in understanding the complex mechanisms of axon growth discussed above, 
but less well understood are their intricate regulation. First, do neurons extend axons constitutively or is axon growth specifically signaled? Because the same signals that induce axon growth are generally critical for neuronal survival, these two functions have been difficult to disentangle-remove putative axon growth signals in vitro or in vivo, and the neurons die. The development of genetic tools to block apoptosis in neurons has recently made it possible to address this question /Goldberg and Barres 2000). For example, in retinal ganglion cells (RGCs), a type of CNS neuron that can be purified and cultured in the complete absence of glial cells, elevating expression of the anti-apoptotic protein Bcl-2 maintains neuronal survival after all trophic signals are withdrawn (Goldberg et al. 2002a). Despite high levels of survival in the absence of exogenous signals, Bcl-2-overexpressing RGCs fail to elaborate axons or dendrites, unless axon growth-inducing signals (see below) were present, clearly demonstrating that axon growth is not a default function of a surviving neuron but must be specifically signaled (Goldberg et al. 2002a). A critical aspect of these experiments with RGCs involved the use of cultures at "clonal density," less than five neurons per square millimeter, which prevented the RGCs from signaling each other with paracrine growth signals (Goldberg et al. 2002a). Peripheral neurons also have a similar requirement for extrinsic signaling of axon growth. For example, when developing dorsal root ganglion (DRG) sensory neurons from transgenic mice that lack the pro-apoptotic protein Bax are cultured in vitro, withdrawal of neurotrophic factors does not induce apoptosis (Lentz et al. 1999). These Bax-/- DRG sensory neurons grow rudimentary axons, but neurotrophins greatly increase axon out growth in vitro (Lentz et al. 1999). Even embryonic peripheral neurons that survive in culture without added trophic factors fail to extend neurites (Lindsay et al. 1985), and adult DRG neurons that do not appear to depend on neurotrophic factors for survival still respond to such factors by increasing axon outgrowth (Lindsay 1988). Taken together, these findings indicate that surviving neurons do not constitutively extend axons and that axon growth must be specifically signaled by extracellular signals.

What are the extracellular signals that induce axon growth?

A great variety of extracellular signals have been found to induce axon growth. The most potent signals are pep tide trophic factors. For instance, a family of peptide trophic factors called neurotrophins, which in mammals include nerve growth factor (NGF), brain-derived neurotrophic factor (BDNF), neurotrophin-3 (NT-3), and neurotrophin-4/5 (NT-4/5), has been studied intensively. Their widespread roles in regulating the developing and adult nervous system have been reviewed extensively (Bibel and Barde 2000). Different neurons are frequently responsive to different trophic factors, and multiple trophic factors can often combine to induce even greater axon growth. In DRG neurons, NGF and BDNF induce more axon growth than either alone (Lindsay et al. 1985); RGCs extend axons equally well in response to BDNF and ciliary neurotrophic factor $(\mathrm{CNTF})$, but both together induce more axon growth than either alone (Goldberg et al. 2002a). Interestingly, in studies that dissociate survival from axon growth, the same peptides that most strongly promote cell survival are the same ones that most strongly promote axon growth. This is even more remarkable considering data suggesting that the survival and axon growth responses to trophic factors diverge inside the neuron, using different intracellular signaling pathways (see discussion below; Atwal et al. 2000; Goldberg et al. 2002a).

Are extracellular signals other than peptide trophic factors sufficient to induce axon elongation? Extracellular matrix molecules like laminin and heparin sulfate proteoglycans, and cell adhesion molecules like L1 and N-Cadherin are widely expressed (Reichardt and Tomaselli 1991; Lafont et al. 1992) and help promote axon growth in vitro and in vivo (Riehl et al. 1996). Their neuronal receptors, including various families of integrins (de Curtis and Reichardt 1993), receptor protein tyrosine phosphatases (for example, see Burden-Gulley and Brady-Kalnay 1999), and IgCAMs and cadherins themselves (for example, see Honjo et al. 2000), are also widely expressed during development but are often down-regulated in adult neurons. Although these signaling interactions can potentiate axon outgrowth in purified CNS neurons if soluble glial or peptide trophic signals are present, so far they do not appear to be sufficient to induce axon growth on their own (Goldberg et al. 2002a). Rather, it appears that they provide a critical substrate along which axons extend, as discussed above, thereby strongly potentiating axon outgrowth. Other adhesion and guidance molecules may also contribute to the signaling of axon elongation, for example as has been described for netrin-1 (Serafini et al. 1994), a well-described axon guidance molecule homologous to laminin. The N-terminal fragment of the guidance molecule slit2 may increase axon elongation in addition to having a better-described axon branching activity (Wang et al. 1999). As axon guidance molecules activate the same growth cone mechanisms discussed above, it is not surprising that their effects may overlap with effects on elongation as well. Finally, other extracellular signals as simple as purine nucleotides may be critical to induce axon growth, although the mechanism of this activity is still mysterious (Benowitz et al. 1998). Therefore peptide trophic factors appear to most strongly induce axon outgrowth, but adhesion molecules can greatly potentiate this growth, and molecules thought to be primarily involved in growth cone guidance may also have some elongation promoting activity.

\section{Where do extracellular signals act to induce axon elongation?}

Where do trophic peptides act-at the cell body, or on the axons themselves? Local application of neurotroph- 
ins to a growth cone is sufficient to enhance the rate of growth cone extension in vitro (Letourneau 1978) and in vivo (Tucker et al. 2001). The definitive answer, however, has come from experiments using Campenot chambers, a powerful technique in which neurons are cultured with their cell bodies in one compartment while their axons grow under a wall into a separate compartment, keeping the culture media in each compartment separated. Classic experiments using cultures of peripheral neurons in these chambers demonstrated the necessity for trophic peptides to signal at the axons and growth cones themselves for the axons to survive and grow (Fig. 3; Campenot 1994). Trophic peptides in the cell body compartment keep the neurons alive, but the axons in the peripheral compartment die back. Amazingly, in these experiments the presence of trophic peptides only in the peripheral (axon) compartment is sufficient to induce survival of the cell body. Therefore, provision of proper growth signals to the axons is as important as providing survival signals to the cell body and point to the importance of providing developing neurons with axon growth signals all along the growth pathway. For example, RGC axon growth is stimulated by soluble signals from the retina, optic nerve, and superior colliculus (Goldberg et al. 2002a), and the en passant survival signals provided to axons in the developing spinal cord are likely to similarly provide en passant axon growth stimulation (Wang and Tessier-Lavigne 1999).

Although trophic factors may act solely at the axon, to induce axon elongation they must also activate pro- cesses at the cell body (see discussion below). How do growth signals at the axon get passed along to the distant cell body, where gene transcription and translation are induced to support survival and axon growth? As in EGFmediated signaling (Vieira et al. 1996), neurotrophin-mediated activation of trk receptors in DRG neuons and PC12 cells leads to endocytosis of activated, ligandbound receptors into clathrin-coated vesicles. These signaling endosomes carry with them the machinery of the ras-raf-MAP kinase signaling cascades, and can continue to activate these pathways once inside the cell (Howe et al. 2001). Neurotrophin signaling endosomes may then be retrogradely transported back to the cell body along microtubules, where they can activate transcriptional regulators and induce new gene expression (Riccio et al. 1997; Watson et al. 1999). In addition, there may be retrograde signaling of neurotrophin-mediated survival signals without retrograde transport of NGFcontaining endosomes (MacInnis and Campenot 2002), raising an interesting hypothesis that survival signals and axon growth or other signals may be carried along separate but complementary pathways. It is not yet known if the retrograde transport of signals from the growth cone is necessary for axon growth if similar signals are already acting at the cell body, as is likely to happen in vivo. Retrograde carriage of neurotrophic signals may modify the signal to carry more information, for example by changing signaling components in different cellular compartments, and may provide crucial signals along the way, for example for maintenance of axo-

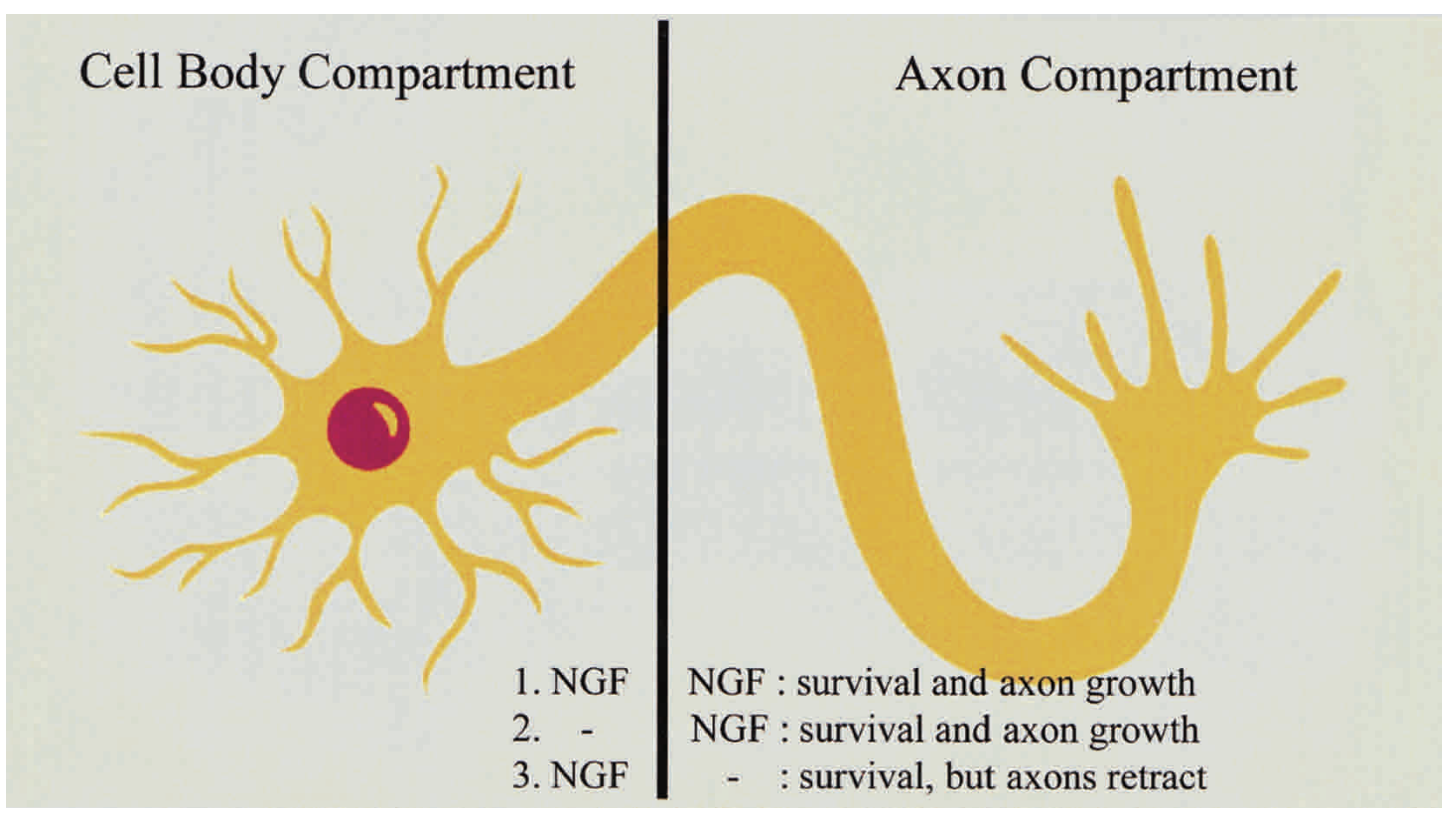

Figure 3. Campenot chambers have proven invaluable in dissecting the functions important to axons from those important to the cell body. In these experiments, a wall separates the culture dish into two or more compartments, and although the axons can grow under the wall into the distal compartment, the contents of the culture media do not diffuse from one side to the other. In this way, factors can be added exclusively to the axons or cell bodies to the exclusion of the other. For example, in the classic experiments dissociating cellular survival from axon growth, neurotrophins such as NGF added to the axon or cell body compartments support neuronal survival, but the neurotrophin must be added specifically to the axon compartment to support the survival and growth of the axons themselves (see text). 
nal structure along its length, or for suppression or support of axon branching.

\section{How do extracellular signals induce axon elongation?}

We know surprisingly little about the intracellular mechanisms by which neurotrophic signals elicit axon growth. Two relevant questions can be addressed in this domain: what are the intermediate signaling pathways that receptors activate to elicit growth, and what are the specific aspects of axon growth that this signaling pathways regulate? A few models have been particularly fruitful in defining which signaling cascades are important for axon growth. Campenot chamber experiments similar to those above showed that for peripheral neurons, both ras-raf-MAP kinase and PI3-kinase-Akt signaling pathways downstream of neurotrophin receptors contribute to axon outgrowth (Atwal et al. 2000). In recent years, significant progress has been made in identifying how these two signaling pathways are activated by neurotrophin receptors; details of these experiments have been reviewed extensively elsewhere (Kaplan and Miller 2000). A second type of experiment takes advantage of neurons in which apoptosis is blocked by knocking out Bax or overexpressing Bcl-2, as discussed above. In Bcl-2-overexpressing RGCs, pharmacologic inhibition of either MAPK or PI3K partially reduce axon outgrowth, but inhibiting both together is necessary to block axon elongation altogether (Goldberg et al. 2002a). In Bax-deficient DRG neurons exposed to NGF, blocking raf, $\mathrm{PI} 3 \mathrm{~K}$, or the PI3K-activated kinase Akt decreases axon elongation, but stimulating the raf-MAPK cascade induces axon elongation, whereas stimulating PI3K or Akt increased axon thickness and branching (Markus et al. 2002). Therefore the data from various investigators continue to be somewhat contradictory and may reflect differing signaling requirements in different neurons isolated at different ages. These data, however, hint at a fascinating complexity of the regulation of these different parameters of axon growth that remains to be more fully studied.

How does the activation of these signaling pathways actually regulate axon growth? At the axon itself, neurotrophic signals may modulate growth cone dynamics, as well as supply and regulate the insertion of membrane and cytoplasmic building blocks. Relevant to the growth cone, for example, are tyrosine kinases such as src, which are activated by both extracellular matrix receptors and by neurotrophin receptors; blocking src activation inhibits the receptor-cytoskeletal linkage critical to engaging the clutch (Suter and Forscher 2001). The p75 neurotrophin receptor appears to constitutively activate rhoA, and neurotrophin binding blocks rhoA activation, leading to axon elongation (Yamashita et al. 1999). The distribution of critical components, for example in cortical neurons the redistribution of $\beta$-actin mRNA to axons is responsive to neurotrophin stimulation in a cAMP/PKA-dependent manner (Zhang et al. 1999). Do growth signals control the rate of addition of new membrane? In goldfish retinal neurons, which unlike mammalian RGCs do regenerate after injury, axonal transport increases after injury presumably to supply the regenerating axon (McQuarrie and Grafstein 1982). Similarly, axonal transport is greater in a growing axon branch close to a target cell than in a suppressed branch distant from its target (Goldberg and Schacher 1987). Neurotrophic signaling of microtubule activity may link the insertion of new membrane to growing processes, as vesicles appear to be preferentially inserted in areas of microtubule instability, such as that found in growth cones (Zakharenko and Popov 1998). Therefore trophic signals may induce elongation, at least in part, by regulating the rate of membrane supply and insertion.

Trophic signals may also directly activate translation of axonal mRNAs. In dendrites, specific mRNAs are likely have a physiologic role in modulating dendritic function, including the changes in synaptic efficacy seen in response to neurotrophins (Kang and Schuman 1996) and activity (Weiler and Greenough 1993; Ouyang et al. 1999; Huber et al. 2000), suggesting that extracellular signals directly modulate local protein synthesis or perhaps stimulate mRNA transport into the dendrite (Knowles and Kosik 1997). Evidence for neurotrophininduced mRNA transport in axons has also been described. As discussed above, $\beta$-actin mRNA is localized to axons and axonal growth cones. This localization can be induced by NT-3 signaling, or by cAMP elevation and subsequent PKA activation (Zhang et al. 1999). This axonal distribution can be inhibited with antisense oligonucleotides that disrupt the binding of the actin mRNA to Zipcode Binding Protein (ZBP-1), which also blocked the NT-3-induced protein localization at the growth cone and decreased growth cone motility (Zhang et al. 2001). Therefore trophic stimulation of axon growth may involve the stimulation of localized mRNA transport and protein synthesis as a mechanism of quickly localizing needed proteins.

What do trophic signals do at the cell body to support axon growth? Almost certainly they activate the transcription and translation of genes needed for general cellular growth. For example, neurotrophic signals up-regulate synthesis of lipids and their synthetic enzymes supporting axon outgrowth (Araki and Wurtman 1997). Transcription factors are now being identified that are both regulated by neurotrophins and required for axon outgrowth, for example, the immediate early gene MafK (Torocsik et al. 2002). Even more interestingly, axon growth requires the transcription of genes specific for axon elongation. This was demonstrated beautifully in experiments showing that after injuring the peripheral axon of DRG neurons in vivo, they switch from a branching mode of axon growth to an elongation mode, and this switch requires new gene transcription (Smith and Skene 1997). Other genes have been found to be upregulated during regeneration (Bonilla et al. 2002), and it is not known whether these and other candidate genes coming from global gene expression studies in progress will have a role in the various processes discussed above, 
or will open up entirely new areas in the study of axon growth.

Are cellular growth and axon growth always linked? As discussed above, cellular growth is not likely to be immediately limiting for axon growth, but are they coordinately regulated? There are certainly examples of cells growing in excess of axon growth needs. Goldfish RGCs hypertrophy after axotomy before regenerating into the optic nerve (Murray and Grafstein 1969; Devadas et al. 2000). Similarly, stabilizing microtubules with nocodazole blocks axon outgrowth but axonal volume continues to increase, suggesting that axoplasm production continues (Rochlin et al. 1996). Why in each of these examples neurons undergo a period of cellular growth that outstrips their need for axon growth is unknown, but it suggests the hypothesis that cellular growth is regulated and perhaps signaled independently of axon growth, and that both cellular growth and axon elongation signals are required for optimal axon growth. The concept that trophic factors are not redundant is supported by recent work on proliferating Schwann cells in vitro, showing that insulin-like growth factor (IGF-1) stimulated cell growth and less so cell division, whereas glial growth factor (GGF) stimulated cell division without cell growth, and together they synergized for maximal proliferative potential (Conlon et al. 2001). In purified RGC cultures, both BDNF and CNTF induce similar rates of axon growth, but the two together induce more than either alone, raising the analogous hypothesis that different trophic factors may be responsible for different facets of axon growth (Goldberg et al. 2002a). What the feedback signals might be that coordinate growth cone procession and supply of critical components, however, is unknown.

\section{Control of neuronal responsiveness to trophic peptides}

An interesting difference between the ability of trophic peptides to promote axon growth by CNS and PNS neurons has been identified. Peptide trophic factors, such as neurotrophins, are sufficient to induce axon growth by purified PNS neurons in culture. In contrast, to elicit axon growth from CNS neurons in culture, peptide trophic signals alone are insufficient. For instance, retinal ganglion cells (RGCs) fail to survive in the presence of such trophic signals as BDNF or CNTF unless their cAMP levels are elevated, either pharmacologically or by depolarization (Meyer-Franke et al. 1995). cAMP elevation and depolarization do not promote axon growth on their own. Similarly, RGCs kept alive with Bcl-2 overexpression extend axons only poorly in response to BDNF, but this axon growth is greatly potentiated by cAMP elevation or by physiological levels of electrical activity, either from endogenous retinal activity or from direct electrical stimulation when cultured on a silicon chip (Goldberg et al. 2002a).

Do neurons have to be electrically active to respond to trophic activities for axon growth? Experiments in vivo suggest that electrical activity is not absolutely required: injecting tetrodotoxin into the eye to block action po- tentials (Shatz and Stryker 1988) or studying the munc18 knockout mouse in which synaptic release of neurotransmitters is essentially eliminated /Verhage et al. 2000) both reveal that RGCs and other CNS neurons successfully elongate their axons to their targets. Recent studies, however, also highlight the possible effects of electrical activity in sculpting axonal morphology. Activity regulates growth cone responsiveness to guidance cues, enhancing netrin responsiveness and inhibiting myelin repulsion (Ming et al. 2001). And, activity shapes the specificity of local connectivity of axons, for example in the selection and elimination of cortical innervation targets (Kalil et al. 1986; Katz and Shatz 1996; Catalano and Shatz 1998). Data on the effect of activity on axon growth have been more controversial. Neuronal activity may increase the rate of axon arborization in vitro and in vivo by stabilizing growing branches (Rashid and Cambray-Deakin 1992; Cohen-Cory 1999; Cantallops et al. 2000). On the other hand, growth cones may collapse acutely in response to electrical stimulation, but then desensitize and recommence axon growth (Fields et al. 1990). Therefore, after a brief accommodation at the growth cone, the longer-term effects of electrical stimulation appear to promote axon growth.

How does activity increase trophic responsiveness in CNS neurons? In the experiments described above, cultured RGCs were plated at clonal density and were not able to contact each other (Goldberg et al. 2002a), so the mechanism is not likely to be autocrine or synaptic. This rules out an activity-dependent secretion of BDNF (Balkowiec and Katz 2000) or the transfer of trophic signals across synapses (Kohara et al. 2001). The effect did, however, depend on TTX-dependent sodium channels and on PKA activity, consistent with the hypothesis that depolarization-mediated increase in cAMP levels elevates trophic responsiveness. Activity increases the density of trophic receptors on the surface of both RGCs and hippocampal neurons (Meyer-Franke et al. 1998; Du et al. 2000), and increasing the levels of surface trkB on RGCs abolishes the need to elevate cAMP for BDNF to promote axon elongation (Goldberg et al. 2002a). These findings suggest that electrical activity potentiates the CNS axon growth response to BDNF by increasing the surface levels of receptors, rather than by amplifying intracellular signaling induced by activation of surface receptors. They also raise the question of whether activity regulates the surface levels of other types of trophic receptors on CNS neurons. Other receptor systems important for axon growth may also be modulated in neurons. For example, in retinal, hippocampal, and cortical neurons but not in peripheral DRG neurons, activation of the GTPase r-ras increases neurite outgrowth on laminin substrates in culture by activation of integrins (Ivins et al. 2000), and increasing the expression of certain integrins increases the ability of adult DRG neurons to extend neurites on various substrates (Condic 2001). A rapid activation of integrin function can be elicited by a nontranscriptional mechanism that may include surface recruitment, for example DRG neurons increase the levels of surface integrins when exposed to low levels of 
laminin ligand in vitro (Condic and Letourneau 1997). It is not yet known if there are physiological, in vivo correlates for these activities. If so, such control mechanisms may provide important insight into the developmental loss of the ability of CNS neurons to regenerate.

This trophic dependence contrasts with PNS neurons, which survive and regenerate their axons in response to trophic peptides in the absence of cAMP elevation or electrical activity, raising the hypothesis that the trophic signaling of axon growth may differ between CNS and PNS neurons. Could this difference contribute to their different abilities to regenerate in vivo? Previous studies have suggested that trophic factor delivery alone or electrical stimulation alone do not induce CNS axonal regeneration. If axon growth normally depends on activity in vivo, and if damaged cells are less active, or elevate cAMP less effectively in response to activity, a CNS neuron's ability to regenerate its axon could be impaired. Therefore it may be crucial to provide trophic peptides as well as signals such as cAMP elevation to ensure an optimal axon growth response (Shen et al. 1999; Goldberg and Barres 2000). Although cAMP elevation has been implicated in overcoming inhibitory signals at the growth cone (Ming et al. 2001), it is interesting to speculate whether some of the effect of cAMP in promoting regeneration in vivo is actually attributable to improving the neurons' response to trophic or other positive peptide signals (Neumann et al. 2002; Qiu et al. 2002).

\section{Intrinsic control of axon growth}

Intrinsic growth ability of CNS neurons is developmentally regulated

Is the rate and extent of axon growth dependent purely on extracellular signals and substrates, or does it also depend on the intrinsic state of the neuron? This is a critical, though largely unanswered, question in research on axon growth and regeneration. Embryonic CNS neurons can regenerate their axons quite readily, but they lose their capacity to regenerate with age (Schwab and Bartholdi 1996; Fawcett 1997). For example, in the spinal cord, axons lose the ability to regenerate between P4 and P20 (Kalil and Reh 1982; Reh and Kalil 1982; Saunders et al. 1992). This developmental loss of regenerative ability has generally been attributed to the maturation of CNS glial cells, both astrocytes and oligodendrocytes, and to the production of CNS myelin, all of which strongly inhibit regenerating axons after injury (Schwab and Bartholdi 1996). Embryonic neurons also develop responsiveness to myelin-associated inhibitors through this period (Bandtlow and Loschinger 1997). In experiments in which a PNS nerve graft (David and Aguayo 1981; Bray et al. 1987) or anti-myelin neutralizing antibodies (Huang et al. 1999) or removal of proteoglycans associated with reactive astrocytes (Moon et al. 2001) allow axons to circumvent contact with these inhibitory CNS glia, however, only a few percent of axons regenerate, and functional recovery typically proceeds remarkably slowly. For example, RGCs take 2 mo to regenerate through a peripheral nerve graft (Aguayo et al. 1987; Bray et al. 1987). These experiments indicate that an inhibitory environment is likely only part of the explanation.

Are the neurons themselves partly responsible? Axons from P2 or older hamster retinas have lost the ability to reinnervate even embryonic tectal explants (Chen et al. 1995). Purkinje cells in cerebellar slices show a similar age-related inability to re-extend axons out of cultured slices (Dusart et al. 1997). This suggests that changes in a CNS neuron's intrinsic ability to grow could also explain this developmental loss of regenerative ability. The lack of postnatal neurons to re-extend their axons might also be explained by the development of glial cells, however, which are largely generated postnatally. Therefore the ability to separate neurons from CNS glia remains critical to determining whether CNS neurons actually change in their intrinsic axon growth ability during development.

By purifying neurons away from nearby glia at various developmental stages, we recently showed that neonatal RGCs undergo a profound, irreversible loss in their intrinsic ability to regenerate their axons (Goldberg et al. 2002b). When cultured in strongly trophic environments in the complete absence of CNS glia and at clonal density, embryonic RGCs extend axons up to 10 times faster than postnatal RGCs. The evidence for this decreased growth ability being intrinsically maintained is twofold. First, we found that embryonic RGCs grew at a faster rate than postnatal RGCs in a variety of environments that should facilitate growth, including in media containing neurotrophic factors, in media conditioned by cells from the embryonic visual pathway, and after transplantation into developing pathways in vivo. In all cases, embryonic RGCs extended their axons at rates substantially higher than did the postnatal RGCs, suggesting that any extrinsic growth-promoting environment is dependent on an intrinsically set maximal growth rate. Second, we found that RGCs purified from either embryonic or postnatal ages, and cultured away from all of the other cell types with which they normally interact, retained their faster or slower growth phenotypes, respectively. Therefore the difference in the abilities of embryonic and postnatal RGCs to elongate axons is not dependent on continued signaling by neighboring cell types, but is intrinsically maintained.

Do these neurons lose their axon growth ability as the result of intrinsic aging? Embryonic RGCs aged up to 10 $\mathrm{d}$ in purified cultures, to the age they would decrease their axon growth ability in vivo, continue to elongate their axons rapidly, suggesting that the change in axon growth ability is signaled by an extrinsic cue (Goldberg et al. 2002b). The decrease in axon growth ability occurs sharply at birth during the period of target innervation, but to our surprise E20 RGCs cocultured with superior collicular slices retain their rapid axon growth ability, suggesting that target contact is responsible for this change. We similarly tested optic nerve and retina, and found that only retinal maturation is sufficient to induce the developmental decrease. We went on to test both soluble and contact-mediated cues from the three major 
cell types that contact RGCs in the retina-amacrine cells, bipolar cells, and retinal glia-and found that only amacrine cell membranes, but not amacrine cell conditioned media, induced E20 RGCs to take on the slower postnatal phenotype. Therefore a membrane-associated cue from these pre-synaptic amacrine cells signals embryonic RGCs to decrease their axon growth ability, but once this signal is sent, the loss is permanent-removal of the amacrine cells does not allow the RGCs to speed up again.

\section{Does dendrite growth ability replace axon} growth ability?

Why would a presynaptic cell type signal these CNS neurons to decrease their intrinsic axon growth ability? Remarkably, at about the same time that neonatal RGCs lose their ability to rapidly elongate axons, they gain the ability to rapidly generate dendrites (Goldberg et al. $2002 \mathrm{~b})$. This increase in dendritic growth ability is not the result of intrinsic aging, but is similarly signaled by a retinal cue. Therefore retinal cues trigger neonatal RGCs to irreversibly switch from an axonal to a dendritic growth mode. We hypothesize that neurons within the inner nuclear layer, which normally relay visual signals from the photoreceptors to RGCs, form synapses onto RGC dendrites at this time, and may signal RGCs to put more energy into expanding their local dendritic connections. Whether the increase in dendritic growth ability and decrease in axon growth ability are the result of the same signal is not addressed by these data /Goldberg et al. 2002b). Are other types of CNS neurons signaled during development to undergo a similar switch? To directly address this question, methods to purify and culture other populations of CNS neurons will need to be developed.

An interesting implication of these data is that the control of axon versus dendrite growth may be largely intrinsic, rather than determined by separate extracellular cues. Axons and dendrites appear to respond to many, or possibly all, of the same growth and guidance signals (for example, see McAllister et al. 1995; Polleux et al. 2000; Xu et al. 2000). It is unknown whether some of the signals found previously to increase dendrite outgrowth, such as bone morphogenic protein-7 (for review, see Higgins et al. 1997), actually modulate the growth mode of the neuron from axonal to dendritic, rather than stimulating dendritic growth cones preferentially. Many of the previous studies that have shown that presynaptic cell types stimulate dendritic growth (for example, see $\mathrm{Ne}$ divi et al. 1998) may reflect a switch in the neurons from axonal to dendritic growth modes, after which the neurons extend dendrites in response to growth signals already present. Our findings therefore suggest that the ability of neurotrophic factors to stimulate axon and dendrite growth may strongly depend on whether a neuron is an axonal or dendritic growth state, and raise the question of the identity of the extracellular signal that induces a dendritic growth mode (Goldberg et al. 2002b).
What molecular changes underlie the developmental loss in rapid axon growth ability?

In response to this amacrine cell-associated cue, RGCs could gradually increase expression of genes that limit axon growth or decrease expression of genes necessary for faster axonal elongation, or both. Almost any of the pathways discussed above-the motor and clutch in the growth cone or the supply of parts fueling process extension-could therefore be regulated at this intrinsic level. For instance, in the developing chick, RGCs lose axon growth responsiveness to laminin either by down-regulating the laminin receptor integrin $\alpha 6 \beta 1$ (Cohen et al. 1989; de Curtis et al. 1991; de Curtis and Reichardt 1993), or by down-regulating the activation of such integrins (Ivins et al. 2000), although they continue to respond to laminin-2 (merosin; Cohen and Johnson 1991). At least for mammalian RGCs, such changes are not responsible for the observed decrease in growth ability, as postnatal RGCs continue to be responsive to laminin1 , as well as a variety of other substrates, and laminin-2 is no more effective than laminin-1 in promoting postnatal RGC axon growth (Goldberg et al. 2002b). Similarly, a difference in trophic receptor levels or responsiveness to trophic signals could explain these differences. For example, depolarization rapidly elevates TrkB receptors on the surface of CNS, but not PNS neurons (Meyer-Franke et al. 1998; Du et al. 2000). Exogenously elevating TrkB levels, however, fails to increase P8 axon growth rates to embryonic levels (Goldberg et al. 2002b). Furthermore, a simple down-regulation of a single receptor cannot account for the change because postnatal RGCs fail to rapidly extend axons in response to all tested axon growth-promoting stimuli and substrates. The anti-apoptotic protein Bcl-2 was proposed as an intrinsic genetic switch that decreases axon growth rate by RGCs (Chen et al. 1997), but Bcl-2 overexpression by purified RGCs in culture neither promotes axon growth nor enhances axon growth in response to neurotrophic signaling in vitro or in vivo (Goldberg et al. 2002b), a result consistent with other findings (Greenlund et al. 1995; Michaelidis et al. 1996; Chierzi et al. 1999; Goldberg and Barres 2000; Lodovichi et al. 2001).

A related question is, what molecular mechanisms could dictate a neuron's axonal or dendritic growth mode? As mentioned above, many of the dendrite "growth stimulators" may actually act via enhancing the neuron's dendritic growth or differentiation mode. Further candidates may come from a better understanding of how axons and dendrites become differentiated. The most useful model for axon and dendrite differentiation has come from studies of cultured embryonic hippocampal neurons by Banker and colleagues over the last two decades. In vitro, these neurons initially extend multiple equivalent neurites; over the course of 5-7 d one becomes the faster growing axon and the rest differentiate into shorter, thicker dendrites (Dotti et al. 1988). Although such a delayed differentiation of axons and dendrites has not been observed in vivo, this model has been enormously fruitful for discerning how axons and 
dendrites are constructed. For example, microtubules in axons and dendrites point in opposite directions-in axons, the microtubules all have their plus ends pointed away from the cell body; in dendrites, microtubules are oriented in both directions. Initially, however, the undifferentiated neurites all have plus-end-distal axonlike microtubules; minus-end-distal microtubules are steadily added to dendrites on neurite differentiation (Baas et al. 1988, 1989). A microtubule motor protein, $\mathrm{CHO} 1 / \mathrm{MKLP} 1$, is responsible for this later minus-enddistal transport, and subsequent differentiation such as the dendritic predominance of golgi and ribosomes discussed above is also lost if CHO1/MKLP1 is depleted (Yu et al. 2000). Therefore, CH01/MLKP1 is one interesting candidate for helping to induce the axon to dendritic switch.

\section{Axon growth and regeneration in the CNS}

Axons that get cut either by injury or disease in the peripheral nervous system (PNS) reinitiate the whole process of axon growth, elongating back to their peripheral targets and restoring sensory and motor function. Yet when axons in the adult mammalian central nervous system (CNS) are severed, they fail to regenerate. The failure of CNS neurons to regenerate their axons is generally ascribed to an inhibitory glial environment; however, emerging data suggest that the extrinsic and intrinsic control of axon growth may also have a significant role. Our understanding of the mechanisms of axon growth has generated much progress in understanding the failure of axons to regenerate in the CNS. For example, understanding that the regulation of both repulsion and collapse of growth cones by inhibitory molecules rely on the same intracellular signaling pathways suggests that manipulating these common regulators can increase regeneration. For example, blocking the growth cone collapsing activity of rho increases RGC regeneration in the inhibitory environment of the optic nerve in vivo (Lehmann et al. 1999), an effect that may be caused in part to the blockade of inhibitory signaling at the growth cone, but also in part by increasing the intrinsic growth ability of the neurons themselves.

Similarly, evidence is accumulating to support a role for neurotrophins in stimulating axon growth and simultaneously signaling the growth cone to ignore inhibitory cues (Cai et al. 1999). On one hand, knowing that signals must be provided to the axons themselves to support axonal survival and growth suggests that glial cells in the CNS may not provide sufficient growth signals to encourage axons to regenerate after injury. Not surprisingly then, the addition of peptide trophic factors enhances regeneration of both CNS and PNS axons in the spinal cord (Schnell et al. 1994; Oudega and Hagg 1996). Are neurotrophins stimulating axon growth, or are they more specifically overcoming myelin inhibition /Cai et al. 1999|? Recent data identified arginase I as a BDNFregulated enzyme in neurons sufficient to overcome inhibition by myelin (Cai et al. 2002), possibly by facilitating the synthesis of other genes or by enhancing cyto- skeletal dynamics such as microtubule polymerization. The identification of this and other genes regulated by neurotrophic factors should allow the further dissection of the mechanisms of stimulating axon growth generally from overcoming glial inhibition specifically.

Does the loss of intrinsic axon growth ability by RGCs (Goldberg et al. 2002b) contribute to their failure to regenerate after injury in the adult? A loss of intrinsic axon growth ability could explain why in many previous experiments regeneration proceeds remarkably slowly, even when glial inhibitory cues have been removed. For example, most RGCs take 2-3 mo to regenerate through peripheral nerve grafts to the superior colliculus (Aguayo et al. 1987; Bray et al. 1987), although the fastest RGCs may extend $1-2 \mathrm{~mm} / \mathrm{d}$ into peripheral nerve grafts after a 5-d delay (Cho and So 1987). This is approximately the rate they extend axons in vitro (Goldberg et al. 2002b), and far slower than the $10 \mathrm{~d}$ they would take if they elongated their axons at $10 \mathrm{~mm} / \mathrm{d}$. Furthermore, adult cortical or retinal neurons or RGCs transplanted into adult white matter elaborate only short, dendritic-like processes (Goldberg et al. 2002b) and as discussed by Condic (2002), suggest that many CNS neurons may undergo a similar switch from an axonal to a dendritic growth mode, and that this switch may underlie the failure of these neurons to regenerate their axons.

Is this switch reversible? Soluble signals from optic nerve glia or peripheral nerve glia, or from retinal or superior collicular cells were not able to reverse the loss of rapid axon growth ability in RGCs in vitro, suggesting that the developmental switch may normally be permanent (Goldberg et al. 2002b). There remains the possibility, however, that other signals, or the discovery and manipulation of genes involved in this transition, may revert the postnatal neurons to their embryonic axon growth ability, and that this may be critical to increase regeneration in the CNS (Cai et al. 2001, 2002).

\section{Do PNS neurons lose their intrinsic axon growth ability?}

In contrast to RGCs, PNS neurons do not dramatically alter their axon growth ability during development. Both during development and in adult regeneration models, sensory axons rapidly grow toward their targets at $\sim 0.5-1$ $\mathrm{mm} / \mathrm{d}$. Different types of PNS neurons have been found to extend axons at different intrinsic rates that vary by several fold (Davies 1989), they maintain this high rate of axonal growth across a broad range of neuronal ages, before and after target innervation (Argiro and Johnson 1982; Davies 1989). Although PNS neurons do not lose their ability to rapidly regenerate their axons during development to nearly the same degree, adult sensory neurons explanted in vitro initially grow in an arborizing, highly branching mode. After a day in culture, they revert into a rapidly elongating, minimally branching mode, and a transcription-dependent switch discussed above controls the competence of these neurons to elongate their axons. This transition can be elicited in vivo by injuring the PNS axon a few days before explanting the neuron, a paradigm called a "conditioning lesion," 
but this change to an elongation mode either in vivo or in vitro typically involves an increase in growth rate of about twofold (Smith and Skene 1997). Therefore, both CNS and PNS neurons show an intrinsic state dependence in their axon growth ability, but whereas PNS neurons remain fairly true to their developmental axon growth ability and quickly revert to this fast elongation when called on to regenerate their axons, RGCs and possibly other CNS neurons dramatically lose their developmental axon growth ability and fail to revert to a rapidly regenerating mode after injury.

What are the transcription-dependent changes that underlie PNS neurons ability to rapidly regenerate? There are many changes in gene expression that occur in peripheral neurons after axotomy, including up-regulation of transcription factors, cytoskeletal proteins, molecular motors that carry material up and down axons, cell adhesion and axon guidance molecules, and trophic factors and receptors (for review, see Tetzlaff and Steeves 2000). But which genes are sufficient, and which are necessary? Using a candidate gene approach, Skene and colleagues recently showed that overexpressing two growth cone proteins, GAP-43 and CAP-23, is sufficient to dramatically increase DRG axon growth in vitro and in the injured spinal cord in vivo (Bomze et al. 2001). Experiments are underway to characterize the differences in axon growth between developing and regenerating sensory neurons. For example, GAP-43 promoter elements are active in developing but not in regenerating zebrafish neurons (Udvadia et al. 2001). Similarly, whereas embryonic DRG neurons depend on the MEK and less-so PI3K signaling pathways for axon growth, regenerating DRG neurons depend on JAK/STAT signaling for axon growth (Liu and Snider 2001). Early data using microarrays to more broadly examine changes in global gene expression between embryonic and adult sensory neurons similarly suggest that adult neurons do not simply revert to embryonic gene expression. Rather, conditioning lesions turn on a distinct, but partially overlapping, set of genes for peripheral regeneration (Bulsara et al. 2002; Griffin et al. 2002). As these studies shed more light on how axons normally grow during development and after injury, they may also reveal clues to the failure of CNS regeneration and the seemingly permanent loss of intrinsic axon growth potential of CNS neurons like RGCs.

\section{Conclusions}

Despite its great importance, our understanding of how axons grow is still in its infancy. Although a great deal of recent progress has been made in understanding the nature of the extracellular signals that induce axon growth, we still know relatively little about the intracellular molecular mechanisms by which these signals are transduced into the neuron and ultimately how they elicit growth. Fortunately, new molecular tools including genomics, proteomics, and RNAi should help us to elucidate novel components of the axon growth machinery that couple transmembrane signaling receptors at the growth cone to the axonal cytoskeleton. In particular, these methods should soon reveal the underlying transcriptional program elicited by peptide trophic factors that triggers axon growth. Determining what are the full roster of genes induced during axon growth, which genes are needed for axon elongation both during development and for regeneration, and whether differences between CNS and PNS neurons in the transcriptional response to injury underlies the failure of CNS neurons to regenerate, remain critical areas of inquiry. Such genetic expression surveys may yield vital clues to how the disparate facets of axon growth are regulated coordinately by extracellular signals and intrinsic neuronal growth states. Finally, broadening our understanding of how axons grow during normal development will help us understand why they fail to regrow after CNS injury.

\section{Acknowledgments}

Brian Bounds' critical help in creating the figures is deeply appreciated, as are Ben Barres' thoughtful comments on this manuscript.

\section{References}

Aguayo, A.J., Vidal-Sanz, M., Villegas-Perez, M.P., and Bray, G.M. 1987. Growth and connectivity of axotomized retinal neurons in adult rats with optic nerves substituted by PNS grafts linking the eye and the midbrain. Ann. N.Y. Acad. Sci. 495: 1-9.

Ahmad, F.J., Echeverri, C.J., Vallee, R.B., and Baas, P.W. 1998. Cytoplasmic dynein and dynactin are required for the transport of microtubules into the axon. J. Cell. Biol. 140: 391401.

Araki, W. and Wurtman, R.J. 1997. Control of membrane phosphatidylcholine biosynthesis by diacylglycerol levels in neuronal cells undergoing neurite outgrowth. Proc. Natl. Acad. Sci. 94: 11946-11950.

Argiro, V. and Johnson, M.I. 1982. Patterns and kinetics of neurite extension from sympathetic neurons in culture are age dependent. J. Neurosci. 2: 503-512.

Atwal, J.K., Massie, B., Miller, F.D., and Kaplan, D.R. 2000. The TrkB-Shc site signals neuronal survival and local axon growth via MEK and P13-kinase. Neuron 27: 265-277.

Baas, P.W., Deitch, J.S., Black, M.M., and Banker, G.A. 1988. Polarity orientation of microtubules in hippocampal neurons: Uniformity in the axon and nonuniformity in the dendrite. Proc. Nat1. Acad. Sci. 85: 8335-8339.

Baas, P.W., Black, M.M., and Banker, G.A. 1989. Changes in microtubule polarity orientation during the development of hippocampal neurons in culture. J. Cell. Biol. 109: 30853094.

Balkowiec, A. and Katz, D.M. 2000. Activity-dependent release of endogenous brain-derived neurotrophic factor from primary sensory neurons detected by ELISA in situ. J. Neurosci. 20: 7417-7423.

Bandtlow, C.E. and Loschinger, J. 1997. Developmental changes in neuronal responsiveness to the CNS myelin-associated neurite growth inhibitor NI-35/250. Eur. J. Neurosci. 9: 27432752.

Bassell, G.J., Zhang, H., Byrd, A.L., Femino, A.M., Singer, R.H., Taneja, K.L., Lifshitz, L.M., Herman, I.M., and Kosik, K.S. 1998. Sorting of $\beta$-actin mRNA and protein to neurites and growth cones in culture. J. Neurosci. 18: 251-265. 
Benowitz, L.I., Jing, Y., Tabibiazar, R., Jo, S.A., Petrausch, B., Stuermer, C.A., Rosenberg, P.A., and Irwin, N. 1998. Axon outgrowth is regulated by an intracellular purine-sensitive mechanism in retinal ganglion cells. J. Biol. Chem. 273: 29626-29634.

Bibel, M. and Barde, Y.A. 2000. Neurotrophins: Key regulators of cell fate and cell shape in the vertebrate nervous system. Genes \& Dev. 14: 2919-2937.

Biernat, J., Wu, Y.Z., Timm, T., Zheng-Fischhofer, Q., Mandelkow, E., Meijer, L., and Mandelkow, E.M. 2002. Protein kinase MARK/PAR-1 is required for neurite outgrowth and establishment of neuronal polarity. Mol. Biol. Cell 13: 40134028.

Bito, H., Furuyashiki, T., Ishihara, H., Shibasaki, Y., Ohashi, K., Mizuno, K., Maekawa, M., Ishizaki, T., and Narumiya, S. 2000. A critical role for a rho-associated kinase, p160ROCK, in determining axon outgrowth in mammalian CNS neurons. Neuron 26: 431-441.

Bomze, H.M., Bulsara, K.R., Iskandar, B.J., Caroni, P., and Pate Skene, J.H. 2001. Spinal axon regeneration evoked by replacing two growth cone proteins in adult neurons. Nat. Neurosci. 4: 38-43.

Bonilla, I.E., Tanabe, K., and Strittmatter, S.M. 2002. Small proline-rich repeat protein $1 \mathrm{~A}$ is expressed by axotomized neurons and promotes axonal outgrowth. J. Neurosci. 22: 1303 1315.

Braga, V. 2002. Cell-cell adhesion and signalling. Curr. Opin. Cell. Biol. 14: 546.

Bray, G.M., Villegas-Perez, M.P., Vidal-Sanz, M., and Aguayo, A.J. 1987. The use of peripheral nerve grafts to enhance neuronal survival, promote growth and permit terminal reconnections in the central nervous system of adult rats. J. Exp. Biol. 132: 5-19.

Brittis, P.A., Lu, Q., and Flanagan, J.G. 2002. Axonal protein synthesis provides a mechanism for localized regulation at an intermediate target. Cell 110: 223-235.

Bulsara, K.R., Dai, H.H., Diehn, M., Brown, P.O., and Skene, J.H. 2002. Distinct, but overlapping, genetic programs for developmental axon growth and adult nerve regeneration. Soc. Neurosci. Abstr. Program No. 734.11.

Burden-Gulley, S.M. and Brady-Kalnay, S.M. 1999. PTPmu regulates N-cadherin-dependent neurite outgrowth. J. Cell. Biol. 144: 1323-1336.

Cai, D., Shen, Y., De Bellard, M., Tang, S., and Filbin, M.T. 1999. Prior exposure to neurotrophins blocks inhibition of axonal regeneration by MAG and myelin via a cAMP-dependent mechanism. Neuron 22: 89-101.

Cai, D., Qiu, J., Cao, Z., McAtee, M., Bregman, B.S., and Filbin, M.T. 2001. Neuronal cyclic AMP controls the developmental loss in ability of axons to regenerate. J Neurosci 21: 47314739.

Cai, D., Deng, K., Mellado, W., Lee, J., Ratan, R.R., and Filbin, M.T. 2002. Arginase I and polyamines act downstream from cyclic AMP in overcoming inhibition of axonal growth MAG and myelin in vitro. Neuron 35: 711-719.

Campbell, D.S. and Holt, C.E. 2001. Chemotropic responses of retinal growth cones mediated by rapid local protein synthesis and degradation. Neuron 32: 1013-1026.

Campenot, R.B. 1994. NGF and the local control of nerve terminal growth. J. Neurobiol. 25: 599-611.

Cantallops, I., Haas, K., and Cline, H.T. 2000. Postsynaptic CPG15 promotes synaptic maturation and presynaptic axon arbor elaboration in vivo. Nat. Neurosci. 3: 1004-1011.

Catalano, S.M. and Shatz, C.J. 1998. Activity-dependent cortical target selection by thalamic axons. Science 281: 559-562.

Chen, D.F., Jhaveri, S., and Schneider, G.E. 1995. Intrinsic changes in developing retinal neurons result in regenerative failure of their axons. Proc. Nat1. Acad. Sci. 92: 7287-7291.

Chen, D.F., Schneider, G.E., Martinou, J.C., and Tonegawa, S. 1997. Bcl-2 promotes regeneration of severed axons in mammalian CNS. Nature 385: 434-439.

Chierzi, S., Strettoi, E., Cenni, M.C., and Maffei, L. 1999. Optic nerve crush: Axonal responses in wild-type and bcl-2 transgenic mice. J. Neurosci. 19: 8367-8376.

Cho, E.Y. and So, K.F. 1987. Rate of regrowth of damaged retinal ganglion cell axons regenerating in a peripheral nerve graft in adult hamsters. Brain Res. 419: 369-374.

Cohen, J. and Johnson, A.R. 1991. Differential effects of laminin and merosin on neurite outgrowth by developing retinal ganglion cells. J. Cell. Sci. Suppl. 15: 1-7.

Cohen, J., Nurcombe, V., Jeffrey, P., and Edgar, D. 1989. Developmental loss of functional laminin receptors on retinal ganglion cells is regulated by their target tissue, the optic tectum. Development 107: 381-387.

Cohen-Cory, S. 1999. BDNF modulates, but does not mediate, activity-dependent branching and remodeling of optic axon arbors in vivo. J. Neurosci. 19: 9996-10003.

Condic, M.L. 2001. Adult neuronal regeneration induced by transgenic integrin expression. J. Neurosci. 21: 4782-4788.

. 2002. Neural development: axon regeneration derailed by dendrites. Curr. Biol. 12: R455-R457.

Condic, M.L. and Letourneau, P.C. 1997. Ligand-induced changes in integrin expression regulate neuronal adhesion and neurite outgrowth. Nature 389: 852-856.

Conlon, I.J., Dunn, G.A., Mudge, A.W., and Raff, M.C. 2001. Extracellular control of cell size. Nat. Cell. Biol. 3: 918-921.

Craig, A.M., Wyborski, R.J., and Banker, G. 1995. Preferential addition of newly synthesized membrane protein at axonal growth cones. Nature 375: 592-594.

Da Silva, J.S. and Dotti, C.G. 2002. Breaking the neuronal sphere: Regulation of the actin cytoskeleton in neuritogenesis. Nat. Rev. Neurosci. 3: 694-704.

David, S. and Aguayo, A.J. 1981. Axonal elongation into peripheral nervous system 'bridges' after central nervous system injury in adult rats. Science 214: 931-933.

Davies, A.M. 1989. Intrinsic differences in the growth rate of early nerve fibres related to target distance. Nature 337: 553 555.

de Curtis, I. and Reichardt, L.F. 1993. Function and spatial distribution in developing chick retina of the laminin receptor $\alpha 6 \beta 1$ and its isoforms. Development 118: 377-388.

de Curtis, I., Quaranta, V., Tamura, R.N., and Reichardt, L.F. 1991. Laminin receptors in the retina: sequence analysis of the chick integrin $\alpha 6$ subunit. Evidence for transcriptional and posttranslational regulation. J. Cell. Biol. 113: 405-416.

Devadas, M., Sugawara, K., Shimada, Y., Sugitani, K., Liu, Z.W., Matsukawa, T., and Kato, S. 2000. Slow recovery of goldfish retinal ganglion cells' soma size during regeneration. Neurosci. Res. 37: 289-297.

de Waegh, S.M., Lee, V.M., and Brady, S.T. 1992. Local modulation of neurofilament phosphorylation, axonal caliber, and slow axonal transport by myelinating Schwann cells. Cell 68: 451-463.

DiTella, M.C., Feiguin, F., Carri, N., Kosik, K.S., and Caceres, A. 1996. MAP-1B/TAU functional redundancy during lamininenhanced axonal growth. J. Cell. Sci. 109 (Pt 2): 467-477.

Dotti, C.G., Sullivan, C.A., and Banker, G.A. 1988. The establishment of polarity by hippocampal neurons in culture. $J$. Neurosci. 8: 1454-1468.

Du, J., Feng, L., Yang, F., and Lu, B. 2000. Activity- and Ca(2+)dependent modulation of surface expression of brain-derived neurotrophic factor receptors in hippocampal neurons. $J$. 
Cell. Biol. 150: 1423-1434.

Dusart, I., Airaksinen, M.S., and Sotelo, C. 1997. Purkinje cell survival and axonal regeneration are age dependent: an in vitro study. J. Neurosci. 17: 3710-3726.

Eng, H., Lund, K., and Campenot, R.B. 1999. Synthesis of $\beta$-tubulin, actin, and other proteins in axons of sympathetic neurons in compartmented cultures. J. Neurosci. 19: 1-9.

Fawcett, J.W. 1997. Astrocytic and neuronal factors affecting axon regeneration in the damaged central nervous system. Cell. Tissue Res. 290: 371-377.

Fields, R.D., Neale, E.A., and Nelson, P.G. 1990. Effects of patterned electrical activity on neurite outgrowth from mouse sensory neurons. J. Neurosci. 10: 2950-2964.

Forscher, P. and Smith, S.J. 1988. Actions of cytochalasins on the organization of actin filaments and microtubules in a neuronal growth cone. J. Cell. Biol. 107: 1505-1516.

Fukata, Y., Itoh, T.J., Kimura, T., Menager, C., Nishimura, T., Shiromizu, T., Watanabe, H., Inagaki, N., Iwamatsu, A., Hotani, H., et al. 2002. CRMP-2 binds to tubulin heterodimers to promote microtubule assembly. Nat. Cell. Biol. 4: 583591.

Futerman, A.H. and Banker, G.A. 1996. The economics of neurite outgrowth - the addition of new membrane to growing axons. Trends Neurosci. 19: 144-149.

Gaete, J., Kameid, G., and Alvarez, J. 1998. Regenerating axons of the rat require a local source of proteins. Neurosci. Lett. 251: 197-200.

Goldberg, D.J. and Schacher, S. 1987. Differential growth of the branches of a regenerating bifurcate axon is associated with differential axonal transport of organelles. Dev. Biol. 124: 35-40.

Goldberg, J.L. and Barres, B.A. 2000. The relationship between neuronal survival and regeneration. Annu. Rev. Neurosci. 23: $579-612$.

Goldberg, J.L., Espinosa, J.S., Xu, Y., Davidson, N., Kovacs, G.T., and Barres, B.A. 2002a. Retinal ganglion cells do not extend axons by default: Promotion by neurotrophic signaling and electrical activity. Neuron 33: 689-702.

Goldberg, J.L., Klassen, M.P., Hua, Y., and Barres, B.A. 2002 b. Amacrine-signaled loss of intrinsic axon growth ability by retinal ganglion cells. Science 296: 1860-1864.

Gould, R.M., Connell, F., and Spivack, W. 1987a. Phospholipid metabolism in mouse sciatic nerve in vivo. J. Neurochem. 48: 853-859.

Gould, R.M., Holshek, J., Silverman, W., and Spivack, W.D. 1987b. Localization of phospholipid synthesis to Schwann cells and axons. J. Neurochem. 48: 1121-1131.

Greenlund, L.J., Korsmeyer, S.J., and Johnson Jr., E.M. 1995. Role of BCL-2 in the survival and function of developing and mature sympathetic neurons. Neuron 15: 649-661.

Griffin, J.W., Price, D.L., Drachman, D.B., and Morris, J. 1981. Incorporation of axonally transported glycoproteins into axolemma during nerve regeneration. J. Cell. Biol. 88: 205214.

Griffin, R.S., Costigan, M., Mills, C.D., Karchewski, L.A., Allchorne, A.J., and Woolf, C.J. 2002. Growth associated gene expression in primary sensory neurons. Soc. Neurosc. Abstr. Program No. 99.1.

Hall, G.F., Chu, B., Lee, S., Liu, Y., and Yao, J. 2000. The single neurofilament subunit of the lamprey forms filaments and regulates axonal caliber and neuronal size in vivo. Cell. Motil. Cytoskeleton 46: 166-182.

Harada, A., Teng, J., Takei, Y., Oguchi, K., and Hirokawa, N. 2002. MAP2 is required for dendrite elongation, PKA anchoring in dendrites, and proper PKA signal transduction. J. Cell. Biol. 158: 541-549.
Harel, R. and Futerman, A.H. 1996. A newly-synthesized GPIanchored protein, TAG-1/axonin-1, is inserted into axonal membranes along the entire length of the axon and not exclusively at the growth cone. Brain Res. 712: 345-348.

Harris, W.A., Holt, C.E., and Bonhoeffer, F. 1987. Retinal axons with and without their somata, growing to and arborizing in the tectum of Xenopus embryos: a time-lapse video study of single fibres in vivo. Development 101: 123-133.

Higgins, D., Burack, M., Lein, P., and Banker, G. 1997. Mechanisms of neuronal polarity. Curr. Opin. Neurobiol. 7: 599604.

Honjo, M., Tanihara, H., Suzuki, S., Tanaka, T., Honda, Y., and Takeichi, M. 2000. Differential expression of cadherin adhesion receptors in neural retina of the postnatal mouse. Invest. Ophthalmol. Vis. Sci. 41: 546-551.

Howe, C.L., Valletta, J.S., Rusnak, A.S., and Mobley, W.C. 2001. NGF signaling from clathrin-coated vesicles: evidence that signaling endosomes serve as a platform for the Ras-MAPK pathway. Neuron 32: 801-814.

Huang, D.W., McKerracher, L., Braun, P.E., and David, S. 1999. A therapeutic vaccine approach to stimulate axon regeneration in the adult mammalian spinal cord. Neuron 24: 639647.

Huber, K.M., Kayser, M.S., and Bear, M.F. 2000. Role for rapid dendritic protein synthesis in hippocampal mGluR-dependent long-term depression. Science 288: 1254-1257.

Ivins, J.K., Yurchenco, P.D., and Lander, A.D. 2000. Regulation of neurite outgrowth by integrin activation. J. Neurosci. 20: 6551-6560.

Job, C. and Eberwine, J. 2001. Localization and translation of mRNA in dendrites and axons. Nat. Rev. Neurosci. 2: 889898.

Kabir, N., Schaefer, A.W., Nakhost, A., Sossin, W.S., and Forscher, P. 2001. Protein kinase c activation promotes microtubule advance in neuronal growth cones by increasing average microtubule growth lifetimes. J. Cell. Biol. 152: 10331044.

Kalil, K. and Reh, T. 1982. A light and electron microscopic study of regrowing pyramidal tract fibers. J. Comp. Neurol. 211: 265-275.

Kalil, R.E., Dubin, M.W., Scott, G., and Stark, L.A. 1986. Elimination of action potentials blocks the structural development of retinogeniculate synapses. Nature 323: 156-158.

Kang, H. and Schuman, E.M. 1996. A requirement for local protein synthesis in neurotrophin-induced hippocampal synaptic plasticity. Science 273: 1402-1406.

Kaplan, D.R. and Miller, F.D. 2000. Neurotrophin signal transduction in the nervous system. Curr. Opin. Neurobiol. 10: 381-391.

Katz, L.C. and Shatz, C.J. 1996. Synaptic activity and the construction of cortical circuits. Science 274: 1133-1138.

Klausner, R.D., Donaldson, J.G., and Lippincott-Schwartz, J. 1992. Brefeldin A: Insights into the control of membrane traffic and organelle structure. J. Cell. Biol. 116: 1071-1080.

Knowles, R.B. and Kosik, K.S. 1997. Neurotrophin-3 signals redistribute RNA in neurons. Proc. Nat1. Acad. Sci. 94: 1480414808.

Koenig, E., Martin, R., Titmus, M., and Sotelo-Silveira, J.R. 2000. Cryptic peripheral ribosomal domains distributed intermittently along mammalian myelinated axons. I. Neurosci. 20: 8390-8400.

Kohara, K., Kitamura, A., Morishima, M., and Tsumoto, T. 2001. Activity-dependent transfer of brain-derived neurotrophic factor to postsynaptic neurons. Science 291: 24192423.

Lafont, F., Rouget, M., Triller, A., Prochiantz, A., and Rousselet, 
A. 1992. In vitro control of neuronal polarity by glycosaminoglycans. Development 114: 17-29.

Lamoureux, P., Altun-Gultekin, Z.F., Lin, C., Wagner, J.A., and Heidemann, S.R. 1997. Rac is required for growth cone function but not neurite assembly. J. Cell. Sci. 110: 635-641.

Lamoureux, P., Buxbaum, R.E., and Heidemann, S.R. 1998. Axonal outgrowth of cultured neurons is not limited by growth cone competition. J. Cell. Sci. 111: 3245-3252.

Lanier, L.M., Gates, M.A., Witke, W., Menzies, A.S., Wehman, A.M., Macklis, J.D., Kwiatkowski, D., Soriano, P., and Gertler, F.B. 1999. Mena is required for neurulation and commissure formation. Neuron 22: 313-325.

Lehmann, M., Fournier, A., Selles-Navarro, I., Dergham, P., Sebok, A., Leclerc, N., Tigyi, G., and McKerracher, L. 1999. Inactivation of rho signaling pathway promotes CNS axon regeneration. J. Neurosci. 19: 7537-7547.

Lein, P.J. and Higgins, D. 1991. Protein synthesis is required for the initiation of dendritic growth in embryonic rat sympathetic neurons in vitro. Brain Res. Dev. Brain Res. 60: 187196.

Lentz, S.I., Knudson, C.M., Korsmeyer, S.J., and Snider, W.D. 1999. Neurotrophins support the development of diverse sensory axon morphologies. J. Neurosci. 19: 1038-1048.

Letourneau, P.C. 1978. Chemotactic response of nerve fiber elongation to nerve growth factor. Dev. Biol. 66: 183-196.

Lin, C.H. and Forscher, P. 1995. Growth cone advance is inversely proportional to retrograde F-actin flow. Neuron 14: 763-771.

Lin, C.H., Espreafico, E.M., Mooseker, M.S., and Forscher, P. 1996. Myosin drives retrograde F-actin flow in neuronal growth cones. Neuron 16: 769-782.

Lindsay, R.M. 1988. Nerve growth factors (NGF, BDNF) enhance axonal regeneration but are not required for survival of adult sensory neurons. J. Neurosci. 8: 2394-2405.

Lindsay, R.M., Thoenen, H., and Barde, Y.A. 1985. Placode and neural crest-derived sensory neurons are responsive at early developmental stages to brain-derived neurotrophic factor. Dev. Biol. 112: 319-328.

Liu, C.W., Lee, G., and Jay, D.G. 1999. Tau is required for neurite outgrowth and growth cone motility of chick sensory neurons. Cell. Motil. Cytoskeleton 43: 232-242.

Liu, R.Y. and Snider, W.D. 2001. Different signaling pathways mediate regenerative versus developmental sensory axon growth. J. Neurosci. 21: RC164.

Lodovichi, C., Di Cristo, G., Cenni, M.C., and Maffei, L. 2001. $\mathrm{Bcl}-2$ overexpression per se does not promote regeneration of neonatal crushed optic fibers. Eur. J. Neurosci. 13: 833-838.

Lu, M., Witke, W., Kwiatkowski, D.J., and Kosik, K.S. 1997. Delayed retraction of filopodia in gelsolin null mice. J. Cell. Biol. 138: 1279-1287.

MacInnis, B.L. and Campenot, R.B. 2002. Retrograde support of neuronal survival without retrograde transport of nerve growth factor. Science 295: 1536-1539.

Markus, A., Zhong, J., and Snider, W.D. 2002. Raf and akt mediate distinct aspects of sensory axon growth. Neuron 35: 65-76.

Martenson, C., Stone, K., Reedy, M., and Sheetz, M. 1993. Fast axonal transport is required for growth cone advance. Nature 366: 66-69.

McAllister, A.K., Lo, D.C., and Katz, L.C. 1995. Neurotrophins regulate dendritic growth in developing visual cortex. Neuron 15: 791-803.

McQuarrie, I.G. and Grafstein, B. 1982. Protein synthesis and axonal transport in goldfish retinal ganglion cells during regeneration accelerated by a conditioning lesion. Brain Res. 251: $25-37$.
Meberg, P.J., Ono, S., Minamide, L.S., Takahashi, M., and Bamburg, J.R. 1998. Actin depolymerizing factor and cofilin phosphorylation dynamics: Response to signals that regulate neurite extension. Cell. Motil. Cytoskeleton 39: 172-190.

Meyer-Franke, A., Kaplan, M.R., Pfrieger, F.W., and Barres, B.A. 1995. Characterization of the signaling interactions that promote the survival and growth of developing retinal ganglion cells in culture. Neuron 15: 805-819.

Meyer-Franke, A., Wilkinson, G.A., Kruttgen, A., Hu, M., Munro, E., Hanson Jr., M.G., Reichardt, L.F., and Barres, B.A. 1998. Depolarization and cAMP elevation rapidly recruit TrkB to the plasma membrane of CNS neurons. Neuron 21: 681-693.

Michaelidis, T.M., Sendtner, M., Cooper, J.D., Airaksinen, M.S., Holtmann, B., Meyer, M., and Thoenen, H. 1996. Inactivation of bcl-2 results in progressive degeneration of motoneurons, sympathetic and sensory neurons during early postnatal development. Neuron 17: 75-89.

Ming, G., Henley, J., Tessier-Lavigne, M., Song, H., and Poo, M. 2001. Electrical activity modulates growth cone guidance by diffusible factors. Neuron 29: 441-452.

Ming, G.L., Wong, S.T., Henley, J., Yuan, X.B., Song, H.J., Spitzer, N.C., and Poo, M.M. 2002. Adaptation in the chemotactic guidance of nerve growth cones. Nature 417: 411418.

Mitchison, T.J. and Cramer, L.P. 1996. Actin-based cell motility and cell locomotion. Cell 84: 371-379.

Mitchison, T. and Kirschner, M. 1988. Cytoskeletal dynamics and nerve growth. Neuron 1: 761-772.

Moon, L.D., Asher, R.A., Rhodes, K.E., and Fawcett, J.W. 2001. Regeneration of CNS axons back to their target following treatment of adult rat brain with chondroitinase ABC. Nat. Neurosci. 4: 465-466.

Mueller, B.K. 1999. Growth cone guidance: First steps towards a deeper understanding. Annu. Rev. Neurosci. 22: 351-388.

Murray, M. and Grafstein, B. 1969. Changes in the morphology and amino acid incorporation of regenerating goldfish optic neurons. Exp. Neurol. 23: 544-560.

Nedivi, E., Wu, G.Y., and Cline, H.T. 1998. Promotion of dendritic growth by CPG15, an activity-induced signaling molecule. Science 281: 1863-1866.

Neumann, S., Bradke, F., Tessier-Lavigne, M., and Basbaum, A.I. 2002. Regeneration of sensory axons within the injured spinal cord induced by intraganglionic cAMP elevation. Neuron 34: 885-893.

Oudega, M. and Hagg, T. 1996. Nerve growth factor promotes regeneration of sensory axons into adult rat spinal cord. Exp. Neurol. 140: 218-229.

Ouyang, Y., Rosenstein, A., Kreiman, G., Schuman, E.M., and Kennedy, M.B. 1999. Tetanic stimulation leads to increased accumulation of $\mathrm{Ca}(2+) /$ calmodulin-dependent protein kinase II via dendritic protein synthesis in hippocampal neurons. J. Neurosci. 19: 7823-7833.

Patel, B.N. and Van Vactor, D.L. 2002. Axon guidance: the cytoplasmic tail. Curr. Opin. Cell. Biol. 14: 221-229.

Polleux, F., Morrow, T., and Ghosh, A. 2000. Semaphorin 3A is a chemoattractant for cortical apical dendrites. Nature 404: 567-573.

Posse de Chaves, E., Vance, D.E., Campenot, R.B., and Vance, J.E. 1995a. Alkylphosphocholines inhibit choline uptake and phosphatidylcholine biosynthesis in rat sympathetic neurons and impair axonal extension. Biochem. J. 312 (Pt 2): $411-417$.

1995b. Axonal synthesis of phosphatidylcholine is required for normal axonal growth in rat sympathetic neurons. J. Cell. Biol. 128: 913-918. 
Posse de Chaves, E.I., Rusinol, A.E., Vance, D.E., Campenot, R.B., and Vance, J.E. 1997. Role of lipoproteins in the delivery of lipids to axons during axonal regeneration. J. Biol. Chem. 272: 30766-30773.

Posse De Chaves, E.I., Vance, D.E., Campenot, R.B., Kiss, R.S., and Vance, J.E. 2000. Uptake of lipoproteins for axonal growth of sympathetic neurons. J. Biol. Chem. 275: 1988319890.

Qiu, J., Cai, D., Dai, H., McAtee, M., Hoffman, P.N., Bregman, B.S., and Filbin, M.T. 2002. Spinal axon regeneration induced by elevation of cyclic AMP. Neuron 34: 895-903.

Rashid, N.A. and Cambray-Deakin, M.A. 1992. N-methyl-Daspartate effects on the growth, morphology and cytoskeleton of individual neurons in vitro. Brain Res. Dev. Brain Res. 67: 301-308.

Reh, T. and Kalil, K. 1982. Functional role of regrowing pyramidal tract fibers. J. Comp. Neurol. 211: 276-283.

Reichardt, L.F. and Tomaselli, K.J. 1991. Extracellular matrix molecules and their receptors: Functions in neural development. Annu. Rev. Neurosci. 14: 531-570.

Riccio, A., Pierchala, B.A., Ciarallo, C.L., and Ginty, D.D. 1997. An NGF-TrkA-mediated retrograde signal to transcription factor CREB in sympathetic neurons. Science 277: 10971100.

Riehl, R., Johnson, K., Bradley, R., Grunwald, G.B., Cornel, E., Lilienbaum, A., and Holt, C.E. 1996. Cadherin function is required for axon outgrowth in retinal ganglion cells in vivo. Neuron 17: 837-848.

Rochlin, M.W., Wickline, K.M., and Bridgman, P.C. 1996. Microtubule stability decreases axon elongation but not axoplasm production. J. Neurosci. 16: 3236-3246.

Roth, L.W., Bormann, P., Wiederkehr, C., and Reinhard, E. 1999. $\beta$-thymosin, a modulator of the actin cytoskeleton is increased in regenerating retinal ganglion cells. Eur. I. Neurosci. 11: 3488-3498.

Ruthel, G. and Hollenbeck, P.J. 2000. Growth cones are not required for initial establishment of polarity or differential axon branch growth in cultured hippocampal neurons. $J$. Neurosci. 20: 2266-2274.

Saunders, N.R., Balkwill, P., Knott, G., Habgood, M.D., Mollgard, K., Treherne, J.M., and Nicholls, J.G. 1992. Growth of axons through a lesion in the intact CNS of fetal rat maintained in long-term culture. Proc. R. Soc. Lond. B. Biol. Sci. 250: $171-180$.

Schmidt, A. and Hall, M.N. 1998. Signaling to the actin cytoskeleton. Annu. Rev. Cell. Dev. Biol. 14: 305-338.

Schnell, L., Schneider, R., Kolbeck, R., Barde, Y.A., and Schwab, M.E. 1994. Neurotrophin-3 enhances sprouting of corticospinal tract during development and after adult spinal cord lesion. Nature 367: 170-173.

Schwab, M.E. and Bartholdi, D. 1996. Degeneration and regeneration of axons in the lesioned spinal cord. Physiol. Rev. 76: 319-370.

Schwarz, A., Rapaport, E., Hirschberg, K., and Futerman, A.H. 1995. A regulatory role for sphingolipids in neuronal growth. Inhibition of sphingolipid synthesis and degradation have opposite effects on axonal branching. J. Biol. Chem. 270: 10990-10998.

Serafini, T., Kennedy, T.E., Galko, M.J., Mirzayan, C., Jessell, T.M., and Tessier-Lavigne, M. 1994. The netrins define a family of axon outgrowth-promoting proteins homologous to C. elegans UNC-6. Cell 78: 409-424.

Shatz, C.J. and Stryker, M.P. 1988. Prenatal tetrodotoxin infusion blocks segregation of retinogeniculate afferents. Science 242: 87-89.

Shaw, G. and Bray, D. 1977. Movement and extension of iso- lated growth cones. Exp. Cell. Res. 104: 55-62.

Shen, S., Wiemelt, A.P., McMorris, F.A., and Barres, B.A. 1999. Retinal ganglion cells lose trophic responsiveness after axotomy. Neuron 23: 285-295.

Smith, D.S. and Skene, J.H. 1997. A transcription-dependent switch controls competence of adult neurons for distinct modes of axon growth. J. Neurosci. 17: 646-658.

Starr, R., Attema, B., DeVries, G.H., and Monteiro, M.J. 1996. Neurofilament phosphorylation is modulated by myelination. J. Neurosci. Res. 44: 328-337.

Steketee, M.B. and Tosney, K.W. 2002. Three functionally distinct adhesions in filopodia: Shaft adhesions control lamellar extension. J. Neurosci. 22: 8071-8083.

Suter, D.M. and Forscher, P. 2000. Substrate-cytoskeletal coupling as a mechanism for the regulation of growth cone motility and guidance. J. Neurobiol. 44: 97-113.

- 2001. Transmission of growth cone traction force through apCAM-cytoskeletal linkages is regulated by Src family tyrosine kinase activity. J. Cell. Biol. 155: 427-438.

Suter, D.M., Errante, L.D., Belotserkovsky, V., and Forscher, P. 1998. The Ig superfamily cell adhesion molecule, apCAM, mediates growth cone steering by substrate-cytoskeletal coupling. J. Cell. Biol. 141: 227-240.

Takei, Y., Teng, J., Harada, A., and Hirokawa, N. 2000. Defects in axonal elongation and neuronal migration in mice with disrupted tau and map1b genes. J. Cell. Biol. 150: 989-1000.

Tanaka, E. and Sabry, J. 1995. Making the connection: cytoskeletal rearrangements during growth cone guidance. Cell 83: 171-176.

Teng, J., Takei, Y., Harada, A., Nakata, T., Chen, J., and Hirokawa, N. 2001. Synergistic effects of MAP2 and MAP1B knockout in neuronal migration, dendritic outgrowth, and microtubule organization. J. Cell. Biol. 155: 65-76.

Tennyson, V.M. 1970. The fine structure of the axon and growth cone of the dorsal root neuroblast of the rabbit embryo. $J$. Cell. Biol. 44: 62-79.

Tetzlaff, W. and Steeves, J.D. 2000. Intrinsic neuronal and extrinsic glial determinants of axonal regeneration in the in jured spinal cord. In Degeneration and regeneration in the nervous system (ed. N.R. Saunders and K.M. Dziegielewska), pp. 93-118. OPA, Amsterdam, The Netherlands.

Toews, A.D., Armstrong, R., Ray, R., Gould, R.M., and Morell, P. 1988. Deposition and transfer of axonally transported phospholipids in rat sciatic nerve. J. Neurosci. 8: 593-601.

Torocsik, B., Angelastro, J.M., and Greene, L.A. 2002. The basic region and leucine zipper transcription factor MafK is a new nerve growth factor-responsive immediate early gene that regulates neurite outgrowth. J. Neurosci. 22: 8971-8980.

Tucker, K.L., Meyer, M., and Barde, Y.A. 2001. Neurotrophins are required for nerve growth during development. Nat. Neurosci. 4: 29-37.

Udvadia, A.J., Koster, R.W., and Skene, J.H. 2001. GAP-43 promoter elements in transgenic zebrafish reveal a difference in signals for axon growth during CNS development and regeneration. Development 128: 1175-1182.

Vance, J.E., Pan, D., Vance, D.E., and Campenot, R.B. 1991. Biosynthesis of membrane lipids in rat axons. J. Cell. Biol. 115: 1061-1068.

Vance, J.E., Pan, D., Campenot, R.B., Bussiere, M., and Vance, D.E. 1994. Evidence that the major membrane lipids, except cholesterol, are made in axons of cultured rat sympathetic neurons. J. Neurochem. 62: 329-337.

Verhage, M., Maia, A.S., Plomp, J.J., Brussaard, A.B., Heeroma, J.H., Vermeer, H., Toonen, R.F., Hammer, R.E., van den Berg, T.K., Missler, M., et al. 2000. Synaptic assembly of the brain in the absence of neurotransmitter secretion. Science 287: 
864-869.

Vieira, A.V., Lamaze, C., and Schmid, S.L. 1996. Control of EGF receptor signaling by clathrin-mediated endocytosis. Science 274: 2086-2089.

Wang, H. and Tessier-Lavigne, M. 1999. En passant neurotrophic action of an intermediate axonal target in the developing mammalian CNS. Nature 401: 765-769.

Wang, K.H., Brose, K., Arnott, D., Kidd, T., Goodman, C.S., Henzel, W., and Tessier-Lavigne, M. 1999. Biochemical purification of a mammalian slit protein as a positive regulator of sensory axon elongation and branching. Cell 96: 771-784.

Watson, F.L., Heerssen, H.M., Moheban, D.B., Lin, M.Z., Sauvageot, C.M., Bhattacharyya, A., Pomeroy, S.L., and Segal, R.A. 1999. Rapid nuclear responses to target-derived neurotrophins require retrograde transport of ligand-receptor complex. J. Neurosci. 19: 7889-7900.

Weiler, I.J. and Greenough, W.T. 1993. Metabotropic glutamate receptors trigger postsynaptic protein synthesis. Proc. Natl. Acad. Sci. 90: 7168-7171.

Weinberger, R., Schevzov, G., Jeffrey, P., Gordon, K., Hill, M., and Gunning, P. 1996. The molecular composition of neuronal microfilaments is spatially and temporally regulated. $J$. Neurosci. 16: 238-252.

Wills, Z., Bateman, J., Korey, C.A., Comer, A., and Van Vactor, D. 1999a. The tyrosine kinase Abl and its substrate enabled collaborate with the receptor phosphatase Dlar to control motor axon guidance. Neuron 22: 301-312.

Wills, Z., Marr, L., Zinn, K., Goodman, C.S., and Van Vactor, D. 1999b. Profilin and the Abl tyrosine kinase are required for motor axon outgrowth in the Drosophila embryo. Neuron 22: 291-299.

Wu, C. and Dedhar, S. 2001. Integrin-linked kinase (ILK) and its interactors: A new paradigm for the coupling of extracellular matrix to actin cytoskeleton and signaling complexes. $J$. Cell. Biol. 155: 505-510.

Xu, B., Zang, K., Ruff, N.L., Zhang, Y.A., McConnell, S.K., Stryker, M.P., and Reichardt, L.F. 2000. Cortical degeneration in the absence of neurotrophin signaling: Dendritic retraction and neuronal loss after removal of the receptor TrkB. Neuron 26: 233-245.

Yamashita, T., Tucker, K.L., and Barde, Y.A. 1999. Neurotrophin binding to the $\mathrm{p} 75$ receptor modulates rho activity and axonal outgrowth. Neuron 24: 585-593.

Yu, W., Cook, C., Sauter, C., Kuriyama, R., Kaplan, P.L., and Baas, P.W. 2000. Depletion of a microtubule-associated motor protein induces the loss of dendritic identity. J. Neurosci. 20: 5782-5791.

Zakharenko, S. and Popov, S. 1998. Dynamics of axonal microtubules regulate the topology of new membrane insertion into the growing neurites. J. Cell. Biol. 143: 1077-1086.

Zhang, H.L., Singer, R.H., and Bassell, G.J. 1999. Neurotrophin regulation of $\beta$-actin mRNA and protein localization within growth cones. J. Cell. Biol. 147: 59-70.

Zhang, H.L., Eom, T., Oleynikov, Y., Shenoy, S.M., Liebelt, D.A., Dictenberg, J.B., Singer, R.H., and Bassell, G.J. 2001. Neurotrophin-induced transport of a $\beta$-actin mRNP complex increases $\beta$-actin levels and stimulates growth cone motility. Neuron 31: 261-275.

Zhang, X. and Poo, M.M. 2002. Localized synaptic potentiation by BDNF requires local protein synthesis in the developing axon. Neuron 36: 675-688.

Zheng, J., Lamoureux, P., Santiago, V., Dennerll, T., Buxbaum, R.E., and Heidemann, S.R. 1991. Tensile regulation of axonal elongation and initiation. J. Neurosci. 11: 1117-1125.

Zheng, J.Q., Kelly, T.K., Chang, B., Ryazantsev, S., Rajasekaran, A.K., Martin, K.C., and Twiss, J.L. 2001. A functional role for intra-axonal protein synthesis during axonal regeneration from adult sensory neurons. J. Neurosci. 21: 9291-9303. 


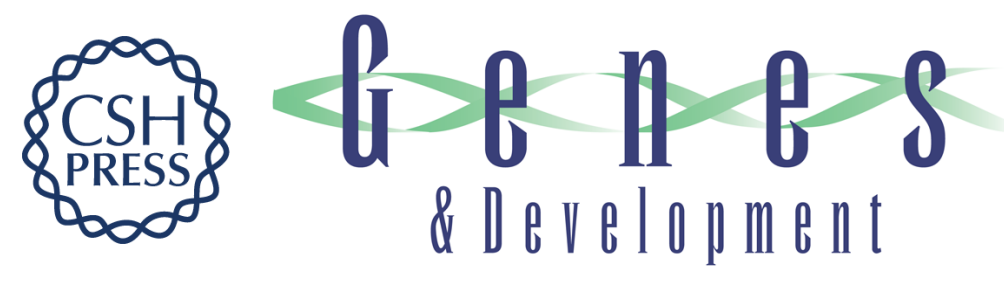

\section{How does an axon grow?}

Jeffrey L. Goldberg

Genes Dev. 2003, 17:

Access the most recent version at doi:10.1101/gad.1062303

References This article cites 180 articles, 86 of which can be accessed free at: http://genesdev.cshlp.org/content/17/8/941.full.html\#ref-list-1

License

Email Alerting Receive free email alerts when new articles cite this article - sign up in the box at the top Service right corner of the article or click here.

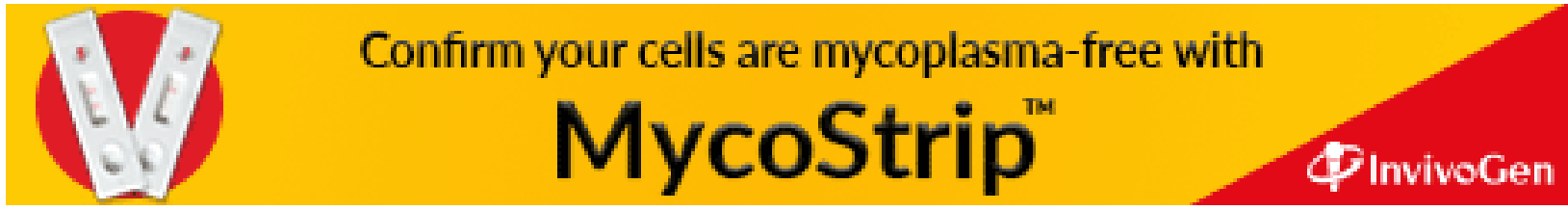

